\title{
Heteroepitaxy of GaP on Silicon for Efficient and Cost-Effective Photoelectrochemical Water Splitting
}

Mahdi Alqahtani ${ }^{1,2^{*}}$, Sanjayan Sathasivam ${ }^{3}$, Fan Cui $^{1}$, Ludmilla Steier ${ }^{4}$, Xueming Xia ${ }^{3}$, Chris Blackman ${ }^{3}$,Eunsoo Kim ${ }^{5}$, Hyunjung Shin ${ }^{5}$, Mourad Benamara 6 , Yuriy I. Mazur ${ }^{6}$, Gregory J. Salamo ${ }^{6}$, Ivan P. Parkin ${ }^{3}$, Huiyun Liu ${ }^{1}$, and Jiang $W u^{1,7^{*}}$

${ }^{1}$ Department of Electronic and Electrical Engineering, University College London, London WC1E 7JE, United Kingdom.

${ }^{2}$ King Abdulaziz City for Science and Technology (KACST), Riyadh 12371, Saudi Arabia ${ }^{3}$ Department of Chemistry, University College London, London WC1H 0AJ, United Kingdom

${ }^{4}$ Department of Chemistry, Imperial College London, London SW7 2AZ, United Kingdom

${ }^{5}$ Department of Energy Science, Sungkyunkwan University, Seoul 440-746 South Korea ${ }^{6}$ Institute for Nanoscience and Engineering, University of Arkansas, Fayetteville, AR 72701, USA

${ }^{7}$ Institute of Fundamental and Frontier Sciences, University of Electronic Science and Technology of China, Chengdu 610054, China

\section{Corresponding Authors}

mahdi.alqahtani.16@ucl.ac.uk

jiangwu@uestc.edu.cn 


\begin{abstract}
Photoelectrochemical production of hydrogen by using sunlight to split water offers a sustainable approach for clean energy generation. III-V Semiconductors have shown the highest efficiencies for photoelectrochemical water splitting but the prohibitive cost of commercial single-crystalline $\mathrm{GaP}$ wafers limit practical use and large-scale application. Here, we report a high-quality $\mathrm{GaP}$ photocathode directly grown on a silicon substrate by solidsource molecular beam epitaxy. The photocathode can be stabilized under acidic electrolyte $1 \mathrm{M} \mathrm{HClO} 4(\mathrm{pH} 0)$ by a combined an amorphous $\mathrm{TiO}_{2}$ layer coated with a molybdenum sulphide $\mathrm{MoS}_{2}$ hydrogen evolution catalyst by atomic layer deposition (ALD). Under simulated AM $1.5 \mathrm{G}$ solar illumination, the $\mathrm{Si} / \mathrm{GaP}$ photocathode yielded a maximum photocurrent density of $0.95\left(\mathrm{~mA} / \mathrm{cm}^{2}\right)$ with a proton reduction onset potential was $467 \mathrm{mV}$ versus the reversible hydrogen electrode. The average Faradaic efficiency of the $\mathrm{Si} / \mathrm{GaP}$ photocathode was measured to be over $73.4 \pm 20.2 \%$ for over 100 minutes. The photoelectrochemical studies for the $\mathrm{Si} / \mathrm{GaP}$ photocathode show the potential for widespread deployment of cost-effective photoelectrodes for hydrogen generation.
\end{abstract}




\section{Introduciton}

Photoelectrochemical water splitting is a promising and sustainable approach for clean energy generation by using sunlight to simultaneously generate hydrogen $\left(\mathrm{H}_{2}\right)$ and oxygen $\left(\mathrm{O}_{2}\right)^{1-3}$. Based on the free energy required to split water, a semiconductor must have a sufficient energy bandgap greater than $1.23 \mathrm{eV}$ and suitable band edges that straddle the redox potentials for water splitting ${ }^{4,5}$. Recent studies of solar hydrogen technologies show that the cost of hydrogen production can be reduced by decreasing the cost of photoelectrodes combined with enhancing their efficiencies ${ }^{6-8}$. However, the development of low cost, efficient, and stable semiconductor photoelectrodes is still a great challenge. For instance, wide bandgap metal-oxides, such as $\mathrm{TiO}_{2}$ and $\mathrm{SrTiO}_{3}$, absorb a small part of the solar spectrum and therefore only low solar-to-hydrogen (STH) conversion efficiency can be achieved $^{9,10}$. On the other hand, group III-V semiconductors are efficient photoelectrodes for PEC water splitting owing to their superior optical properties and appropriate band gaps in the visible range, but their performance over time is limited by photocorrosion in alkaline or acidic electrolytes ${ }^{11-14}$. Importantly, the relatively high cost of III-V materials can not meet the demands for large-scale hydrogen production. III-V semiconductors are generally grown on native III-V substrates, which are a few orders of magnitude more expensive than silicon substrates. Given the dominant role of $\mathrm{Si}$ in the photovoltaic industry and possibility for III$\mathrm{V} / \mathrm{Si}$ tandem PEC cells, hetero-integration of III-V semiconductors and $\mathrm{Si}$ is an attractive approach for cost-effective and efficient PEC cells.

A silicon substrate is not typically used for heteroepitaxy of III-V semiconductors due to the lattice mismatch and incompatible thermal expansion coefficients, which leads to a high density of threading dislocations. Recently, some III-V semiconductors, such as gallium phosphide $(\mathrm{GaP})$, have been shown to overcome these obstacles due to the low lattice mismatch between $\mathrm{GaP}$ and $\mathrm{Si}(0.36 \% \text { at room temperature })^{15}$. Furthermore, GaP is an attractive photocathode for PEC water splitting due to a high conduction band energy and a suitable band gap $(2.25 \mathrm{eV})$, which can provide a maximum photocurrent density of 10 $\left(\mathrm{mA} / \mathrm{cm}^{2}\right)$ under one sun solar illumination ${ }^{16}$. In particular, a few studies on GaP photocathodes and photoanodes have been carried out ${ }^{14}$ 17-19. For example, a GaP photocathode has shown a high open circuit voltage of $710 \mathrm{mV}$ versus reversible hydrogen electrode (RHE) when using it in a heterojunction with a $\mathrm{n}-\mathrm{TiO}_{2}$ layer in an acidic aqueous solution under one sun illumination ${ }^{17}$. Distinct improvements in the performance of GaP photocathodes have also been shown by using Pt-modified GaP nanowires (NWs) grown on commercial single-crystalline GaP wafers ${ }^{14}$. In spite of the relatively high performance, prior 
work on GaP photocathodes has primarily focused on commercial single-crystal wafers, which limits the practical use due to their prohibitive cost. In this work, a high-quality GaP photocathode is directly grown on a silicon substrate by solid-source molecular beam epitaxy (MBE). Under one sun illumination, the GaP photocathode on Si shows a high photocurrent density of $0.95\left(\mathrm{~mA} / \mathrm{cm}^{2}\right)$ and onset potential of $0.467 \mathrm{~V}$, respectively. Furthermore, with an amorphous $\mathrm{TiO}_{2}$ protection layer and $\mathrm{MoS}_{2}$ catalysts, the $\mathrm{GaP}$ photocathode shows the additon of high stability for $3 \mathrm{~h}$ under continuous simulated solar light illumination in aqueous solution $\mathrm{HClO}_{4}(\mathrm{pH}$ ). The Faradaic efficiency of the $\mathrm{Si} / \mathrm{GaP}$ photocathode averages over $73.4 \pm 20.2 \%$ for over 100 minutes, which is closely comparable to that of a GaP photocathode on commercial single-crystalline substrate. Both the good efficiency and stability of the $\mathrm{Si} / \mathrm{GaP}$ photocathodes confirm the advantages of the hetero-integrated III-V/Si system.

\section{Results and discussion}

\section{Heteroepitaxy and Photoelectrochemical Behavior of GaP on Si}

In this work, GaP thin films were directly grown on silicon substrates by molecular beam epitaxy. Figure. 1a shows a cross-sectional transmission electron microscopy (TEM) image of the $\mathrm{Si} / \mathrm{GaP}$ interface. A sharp interface with no antiphase boundary was observed. An atomic force microscopy (AFM) image of the GaP film grown on a silicon substrate is shown in Figure. 1b. The AFM image shows a very flat surface with a root mean square roughness as low as $0.39 \mathrm{~nm}$. A large-scale AFM image also confirms that the GaP film is highly smooth and free of APDs, as shown in Supplementary Information Figure. S1. A cross-sectional scanning TEM image of the $\mathrm{Si} / \mathrm{GaP}$ heterostructure over a large area at low magnification is shown in Figure. 1c. Although a high density of threading dislocations was generated at the $\mathrm{Si} / \mathrm{GaP}$ interface, only a small number of number of dislocations propagated towards the upper part of the GaP film. The threading dislocation density in the upper GaP layer is estimated to be only $\sim 1-3 \times 10^{6} \mathrm{~cm}^{-2}$ by TEM measurements, despite no dislocation filter layers being used in the buffer. This value is in agreement with the pit density measured from a $10 \mu \mathrm{m} \times 10 \mu \mathrm{m}$ AFM image (Supplementary Information Figure. S2).

Symmetric (004) X-ray $\omega$-2 2 scans of the GaP film grown on Si were performed. Figure. 1d shows the $\omega-2 \theta$ curves for the $\mathrm{Si}(004)$ and $\mathrm{GaP}(004)$ reflections, respectively. The $\mathrm{GaP}(004)$ peak shows a full width at half maximum (FWHM) as narrow as 162 arcsec. The FWHM is directly related to the dislocation density, and the low value of the FWHM indicates a low density of dislocations. The optical properties of a single-crystalline GaP wafer (black curve) 
and the GaP film grown directly on $\mathrm{Si}$ substrate (red curve) were further studied using photoluminescence (PL) spectroscopy, as shown in Figure 1f. Similar to the GaP wafer, the broad PL peak of the Si/GaP film can be fitted with two peaks (Supplementary Information Figure. S3). The primary emission peaks for both the $\mathrm{GaP}$ wafer and the $\mathrm{Si} / \mathrm{GaP}$ film were located at approximately $\sim 600 \mathrm{~nm}(2.1 \mathrm{eV})$, which corresponds to the emission from dopant states close to the band edge ${ }^{20}$. A weak peak was observed at around $550 \mathrm{~nm}(2.25 \mathrm{eV})$, which matches the primary indirect energy gap of $\mathrm{GaP}$. The $\mathrm{Si} / \mathrm{GaP}$ film remains about $50 \%$ of the PL intensity for the peak at $600 \mathrm{~nm}$ and nearly unchanged PL intensity at $550 \mathrm{~nm}$, compared with the single-crystalline $\mathrm{GaP}$ wafer. The reduced $\mathrm{PL}$ at $600 \mathrm{~nm}$ of the $\mathrm{Si} / \mathrm{GaP}$ sample maybe due to a lower doping concentration in the $\mathrm{GaP}$ film grown on $\mathrm{Si}$. On the other hand, the nearly unchanged emission intensity at $550 \mathrm{~nm}$ indicates the good optical properties of the $\mathrm{Si} / \mathrm{GaP}$ film.

\section{Photoelectrochemical performance of GaP photocathodes on $\mathrm{Si}$}

It is commonly known that III-V semiconductors, e.g. GaP, are readily susceptible to corrosion in aqueous solution during PEC water splitting ${ }^{11,14,17-19}$. Therefore, it is important to have a suitable protection layer as well as a catalyst to accelerate the charge transfer to the semiconductor/electrolyte interface, which reduces photocorrosion and surface recombination $^{21}$. In previous studies have shown that amorphous leaky titanium dioxide $\left(\mathrm{TiO}_{2}\right)$ film grown by atomic layer deposition (ALD) to protect photoelectrodes (e.g. photocathode and photoanode) because it provides a favorable surface energy band bending, allowing for electrons transfer to electrolyte ${ }^{11,12,17,22-24}$. Therefore, in this study, a $10 \mathrm{~nm}$ amorphous $\mathrm{TiO}_{2}$ thin film was deposited by ALD onto the $\mathrm{Si} / \mathrm{GaP}$ photocathode surface and a p-type single-crystalline GaP reference photocathode, respectively. The $\mathrm{TiO}_{2}$ layer is used as a protective layer to prevent photocorrosion of the GaP absorber during the PEC test. In addition, Pt was deposited into the surfaces of both GaP photocathodes as an efficient catalyst for the hydrogen evolution reaction (HER) to enhance PEC hydrogen production as shown in Figure. 2a. Both the cross-sectional scanning TEM (STEM) image and energy dispersive Xray spectroscopy (EDS) mapping show a well-defined amorphous $\mathrm{TiO}_{2}$ layer deposited onto the GaP surface (Figure. 2b and Supplementary Information Figure. S4 and Figure. S5). The STEM and EDS measurements also confirm a $10 \mathrm{~nm}$ thick Pt co-catalyst layer deposited by sputtering onto the $\mathrm{TiO}_{2}$ protection layers of the GaP-on-Si photocathode and the singlecrystalline $\mathrm{GaP}$ reference photocathode. The two photocathodes are denoted as $\mathrm{Si} / \mathrm{GaP}-\mathrm{TiO}_{2}-$ $\mathrm{Pt}$ and $\mathrm{GaP}_{-} \mathrm{TiO}_{2}-\mathrm{Pt}$. Both photocathodes were measured by linear sweep voltammetry 
scanning in $1 \mathrm{M} \mathrm{HClO}_{4}$ electrolyte ( $\left.\mathrm{pH} 0\right)$ under one sun irradiation for photoelectrochemical water splitting. Detailed description for all materials and measurements used in this study are giving in the Method section.

The photocurrent density $(\mathrm{J})$ versus potential $(\mathrm{V})$ for the $\mathrm{GaP}$ photocathodes are shown in Figure. 2c. Under one sun AM 1.5G illumination, the $\mathrm{Si} / \mathrm{GaP}-\mathrm{TiO}_{2}-\mathrm{Pt}$ photocathode shows a saturated photocurrent density of $0.96\left(\mathrm{~mA} / \mathrm{cm}^{2}\right)$ at $-0.80 \mathrm{~V}$ versus reversible hydrogen electrode (RHE) and onset potential of approximately $0.477 \mathrm{~V}$ versus RHE. In comparison, the $\mathrm{GaP}_{-}-\mathrm{TiO}_{2}-\mathrm{Pt}$ reference photocathode showed a saturated photocurrent of $1.74\left(\mathrm{~mA} / \mathrm{cm}^{2}\right)$ at $-0.80 \mathrm{~V}$ versus RHE with an onset potential at $0.487 \mathrm{~V}$ versus RHE. The incident photon-tocurrent conversion efficiency (IPCE) was evaluated for the GaP photocathodes at $-0.80 \mathrm{~V}$ versus RHE, as shown in Figure 2d. The IPCE values of the $\mathrm{Si} / \mathrm{GaP}-\mathrm{TiO}_{2}-\mathrm{Pt}$ and $\mathrm{GaP}_{-}-\mathrm{TiO}_{2}-\mathrm{Pt}$ photocathodes are $18.3 \%$ and $36.2 \%$ at $400 \mathrm{~nm}$, respectively. The reduced IPCE for the $\mathrm{Si} / \mathrm{GaP}-\mathrm{TiO}_{2}-\mathrm{Pt}$ photocathode is due to a lower electron diffusion length in the $\mathrm{GaP}$ film on $\mathrm{Si}$, which is in agreement with the J-V measurements. In the range 450-500 nm, the IPCE of both photocathodes drops sharply due to the weak absorption in indirect bandgap $\mathrm{GaP}(\sim 2.26 \mathrm{eV})$. The slightly reduced onset potential of the $\mathrm{Si} / \mathrm{GaP}-\mathrm{TiO}_{2}-\mathrm{Pt}$ photocathode compared to that of the $\mathrm{GaP}$ reference photocathode is attributed to the observable crystal defects such as threading dislocations. Nonetheless, the penalty paid to reduce the cost is minor; the reduction in onset potentail is only $10 \mathrm{mV}$ and the photocurrent density remains about $55.2 \%$ of that of the photocathode reference. Further optimization of growth conditions, e.g. using dislocation filter layers, may lead to further reduction of defects and improvements to the photocathode performance.

\section{Structural modification of GaP with $\mathrm{MoS}_{2}$ co-catalyst}

Earth-abundant catalysts such as molybdenum sulphide $\left(\mathrm{MoS}_{2}\right)$ are promising alternatives to precious metals such as platinum, ruthenium, and iridium. Moreover, $\mathrm{MoS}_{2}$ has shown a high activity for hydrogen evolution reaction in strong acid conditions ${ }^{21,} 25$. Therefore, to demonstrate the potential for further cost reduction, $\mathrm{TiO}_{2}$ and $\mathrm{MoS}_{2}$ thin layers were deposited by $\mathrm{ALD}$ onto the $\mathrm{Si} / \mathrm{GaP}$ photocathode and single-crystalline $\mathrm{GaP}$ reference photocathode as the surface protection layer and co-catalyst layer, respectively, as described in the Methods section. The two new photocathodes based on the $\mathrm{Si} / \mathrm{GaP}$ and single-crystalline GaP reference photocathodes are denoted as $\mathrm{Si} / \mathrm{GaP}-\mathrm{TiO}_{2}-\mathrm{MoS}_{2}$ and $\mathrm{GaP}-\mathrm{TiO}_{2}-\mathrm{MoS}_{2}$, respectively. The structural properties of the $\mathrm{MoS}_{2}$ modified surface were analysed by STEM and EDS, as 
shown in Figure. 3a. The cross-sectional STEM images of the $\mathrm{GaP}-\mathrm{TiO}_{2}-\mathrm{MoS}_{2}$ interfaces show well-defined junctions between the layers (Supplementary Information Figure. S6). The individual layers are also well resolved from the EDS mapping in Figure. 3b, indicating good layer compactness and little intermixing at the interface. Compared with the Pt layer, the $\mathrm{MoS}_{2}$ is not as dense but thicker with a larger surface area. The $\mathrm{MoS}_{2}$ layer was about $20 \mathrm{~nm}$ thick and consisted of needle-like features protruding from the flat and uniform $\mathrm{TiO}_{2}$ layer. As shown in Figure. 3b and Supplementary Information Figure. S7, the corresponding EDS mapping and line-profiling graph also provides quantitative evidence for the composition of the individual layers as well as their thickness $(20 \mathrm{~nm} \mathrm{MoS} 2$ and $10 \mathrm{~nm} \mathrm{TiO}$ ).

As shown in Figure 3c, the $\mathrm{Si} / \mathrm{GaP}-\mathrm{TiO}_{2}-\mathrm{MoS}_{2}$ photocathode exhibited a photocurrent onset potential of $0.46 \mathrm{~V}$ versus RHE and a saturated photocurrent density of $0.95 \mathrm{~mA} \mathrm{~cm} \mathrm{~cm}^{-2}$. In contrast, the $\mathrm{MoS}_{2}$-modified $\mathrm{GaP}$ reference photocathode has an onset potential of about $0.657 \mathrm{~V}$ versus RHE and saturated photocurrent density of $1.53 \mathrm{~mA} \mathrm{~cm}^{-2}$. As shown in Figure $3 \mathrm{~d}$, the incident photon-to-current efficiency (IPCE) at $400 \mathrm{~nm}$ was $34.1 \%$ for the $\mathrm{GaP}^{-\mathrm{TiO}_{2}-}$ $\mathrm{MoS}_{2}$ photoelectrode and $23.8 \%$ for $\mathrm{Si} / \mathrm{GaP}-\mathrm{TiO}_{2}-\mathrm{MoS}_{2}$. The IPCE of all photocathodes decrease towards longer wavelengths (> $550 \mathrm{~nm}$ ). Again, by using $\mathrm{MoS}_{2}$ co-catalyst instead of Pt co-catalyst, the performance of the GaP photocathode grown on $\mathrm{Si}$ substrate is still remarkable, with comparable onset potential photocurrent density compared to the state-ofthe-art $\mathrm{GaP}$ photocathodes ${ }^{17-19}$, 26. More importantly, GaP photocathodes grown on $\mathrm{Si}$ substrates with low-cost co-catalysts show a promising approach towards cost-effective hydrogen generation. To gain further insight into the PEC performance of the $\mathrm{Si} / \mathrm{GaP}-\mathrm{TiO}_{2}-$ $\mathrm{MoS}_{2}$ photocathode, hydrogen production for both photocathodes was measured over $100 \mathrm{~min}$ by chronoamperometry under illumination in a gas-tight photoelectrode cell using a Clark electrode sensor (Supplementary Information Figure. S8 and S9). As shown in Figure. 3e, the $\mathrm{Si} / \mathrm{GaP}_{-} \mathrm{TiO}_{2}-\mathrm{MoS}_{2}$ reached a calculated Faradaic efficiency (FE) of $73.4 \pm 20.2 \%$ after a $\sim 25$ min induction period (Supplementary Information Figure. S10). Figure $3 \mathrm{f}$ shows that the GaP$\mathrm{TiO}_{2}-\mathrm{Pt}$ photocathode reached a $\mathrm{FE}$ of $105.4 \pm 8.7 \%$ after a much longer induction period of 90 min (Supplementary Information Figure. S10). Part of the initially lower FE might be due to a delay in equilibration of the $\mathrm{H}_{2}$ concentration in solution and gas phases. Note that the Clark sensor was positioned in the gas phase. Another delay might have been caused by an activation time of the catalyst layers. The measurements were set at a constant potential, and the 'noisy' photocurrent and $\mathrm{H}_{2}$ production in Figure. 3e-f originate from accumulation of gas 
bubbles at the photocathode surface and sequentially sudden release of gas bubbles (Supplementary Information Figure. S11).

\section{GaP Photocathodes stability}

The stability of GaP photocathodes was evaluated for hydrogen evolution under one sun AM1.5 simulated solar illumination, as shown in Figure. 4 (a-b). These electrodes are configured with a constant potential controlled at zero $\mathrm{V}$ versus $\mathrm{RHE}$ in $\mathrm{HClO}_{4}(\mathrm{pH} 0)$ electrolyte. As shown in Figure 4a, for the initial stability of the electrodes evaluated, all the photocathodes exhibited rather good stability of photocurrents over the first $30 \mathrm{~min}$ (Figure 4a). However, for the GaP photocathodes with Pt co-catalysts, both $\mathrm{Si} / \mathrm{GaP}_{-} \mathrm{TiO}_{2}-\mathrm{Pt}$ and GaP$\mathrm{TiO}_{2}$-Pt photoelectrode already exhibited some photocurrent decay, which may be attributed to removal of $\mathrm{Pt}$ catalyst from the surface. Long-term stability of all photocathodes were measured at $0 \mathrm{~V}$ versus RHE for $3 \mathrm{~h}$, as shown in Figure. $4 \mathrm{~b}$. The photocurrent density of the $\mathrm{Si} / \mathrm{GaP}-\mathrm{TiO}_{2}-\mathrm{MoS}_{2}$ photocathode is stable at $-0.89 \mathrm{~mA} \mathrm{~cm}$ for $3 \mathrm{~h}$ under continuous simulated solar light illumination, which is attributed to the high activity $\mathrm{MoS}_{2}$ for hydrogen evolution reaction in strong acidic conditions. On the contrary, the photocurrent density for Pt-modified GaP photocathodes, both $\mathrm{Si} / \mathrm{GaP}-\mathrm{TiO}_{2}-\mathrm{Pt}$ and $\mathrm{GaP}-\mathrm{TiO}_{2}-\mathrm{Pt}$, gradually dropped from $1.4 \mathrm{~mA} \mathrm{~cm}^{-2}$ to $0.8 \mathrm{~mA} \mathrm{~cm} \mathrm{~m}^{-2}$ and from $0.6 \mathrm{~mA} \mathrm{~cm}^{-2}$ to $0.48 \mathrm{~mA} \mathrm{~cm}^{-2}$ respectively, which is attributed to the failure of the $\mathrm{TiO}_{2}$ protection layer and significant photocorrosion of the electrode due to possible removal of Pt catalysts from the surface.

To compare the degree of photocorrosion of two GaP photocathodes grown on Si substrates, the surface morphology was studied by SEM, as shown in Figure. 4(c-d). The SEM images of the surfaces of the $\mathrm{MoS}_{2}$-modified $\mathrm{GaP}$ and Pt-modified GaP photocathodes show distinct differences in morphology after the stability test. Both photocathodes show some pits on the surface indicating photocorrosion, however, the $\mathrm{MoS}_{2}$-modified surface shows fewer surface pits compare to the Pt-modified surface. The pits also appear to be more elongated and deeper on the Pt-modified $\mathrm{GaP}$ surface, suggesting severe photocorrosion (Supplementary Information Figure. S12). AFM images of both photocathodes after stability testing are shown in figure 4e-f. The surface roughness of the Pt-modified electrode is significantly worse than that of the $\mathrm{MoS}_{2}$-modified electrode. The Z-scales of the AFM images in Figure. 4e-f are 30 $\mathrm{nm}$ and $800 \mathrm{~nm}$, respectively, and the RMS roughness of the Pt-modified GaP electrode measured over a $20 \mu \mathrm{m} \times 20 \mu \mathrm{m}$ area is over one order of magnitude higher than that of the $\mathrm{MoS}_{2}$-modified electrode (Supplementary Information Figure. S13). Additionally, the pit 
depth on the $\mathrm{MoS}_{2}$-modified electrode is only about $30 \mathrm{~nm}$ while it can be over $500 \mathrm{~nm}$ on the Pt-modified GaP surface, confirming distinct improvement in stability using $\mathrm{MoS}_{2}$ cocatalysts (Supplementary Information Figure. S13).

X-ray photoelectron spectroscopy (XPS) was performed to determine the surface composition and chemical state of the Si/GaP photocathodes, as shown in Figure. 5. Before PEC testing of the $\mathrm{Si} / \mathrm{GaP}-\mathrm{TiO}_{2}-\mathrm{MoS}_{2}$ photocathode, only peaks for $\mathrm{Mo}, \mathrm{S}$, and $\mathrm{O}$ were seen as expected due to the $\mathrm{MoS}_{2}$ overlayer (Figure. 5a-d). The deconvolution of the Mo 3d peaks produced two sets of doublets, with the primary Mo $3 \mathrm{~d}_{5 / 2}$ peak centred at $229.0 \mathrm{eV}$ and corresponding to $\mathrm{Mo}^{4+}$ associated with $\mathrm{MoS}_{2}$. The secondary $3 \mathrm{~d}_{5 / 2}$ peak was centred at $230.9 \mathrm{eV}$ and belongs to $\mathrm{Mo}^{4+}$ and is ascribed to surface oxidation. The $\mathrm{S} 2 \mathrm{p}$ region showed an overlapping doublet separated by $1.16 \mathrm{eV}$ with the $2 \mathrm{p}_{3 / 2}$ peak at $162.1 \mathrm{eV}$ corresponding to $\mathrm{MoS}_{2}$. After PEC analysis, $\mathrm{MoS}_{2}$ still remained on the surface. Similar to the spectra before PEC testing, Mo $3 \mathrm{~d}_{5 / 2}$ peaks were observed at $228.7 \mathrm{eV}\left(\mathrm{Mo}^{4+}, \mathrm{Mo}-\mathrm{S}\right)$ and $230.0 \mathrm{eV}\left(\mathrm{Mo}^{4+}\right.$, Mo-O) with an S $2 \mathrm{p}_{3 / 2}$ peak observed at $161.7 \mathrm{eV}\left(\mathrm{S}^{2-}, \mathrm{S}-\mathrm{Mo}\right)$. Due to the robust nature of the $\mathrm{MoS}_{2}$ layer, no signals were observed for Ti, Ga and P. The surface composition and chemical state of the $\mathrm{Si} / \mathrm{GaP}_{-}-\mathrm{TiO}_{2}-\mathrm{Pt}$ photocathode are shown in Fig 5e-h. Before PEC test, peaks were only observed for Pt $4 \mathrm{f}$ with no signals being seen for Ti, O, Ga and P. This is expected due to the dense nature of the $\mathrm{Pt}$ surface layer. The $\mathrm{Pt} 4 \mathrm{f}$ doublet was deconvoluted using an asymmetric line shape to give the $\mathrm{Pt} 4 \mathrm{f}_{7 / 2}$ peak centre at $71.0 \mathrm{eV}$ corresponding to metallic Pt. After PEC test, no Pt peaks was seen suggesting complete degradation of the metallic layer in the acidic solution. Surprisingly, no Ti was observed suggesting that the $\mathrm{TiO}_{2}$ layer was also degraded. An oxygen signal was see observed, but this is thought to be due to the surface oxidation of $\mathrm{Ga}$ in the $\mathrm{GaP}$. The $\mathrm{Ga} 2 \mathrm{p}_{3 / 2}$ peak was centred at $1117.7 \mathrm{eV}$ corresponding to $\mathrm{Ga}$ in the 3+ oxidation state. For P $2 p$, two sets of doublets were observed, with one $2 \mathrm{p}_{3 / 2}$ at $129.0 \mathrm{eV}$ that belongs to $\mathrm{P}$ in the 3- state bound to $\mathrm{Ga}$ while a smaller transition at $133.1 \mathrm{eV}$ corresponds to $5+$ oxidation state that belongs to the metal phosphate form. In the end, the $\mathrm{MoS}_{2}$-modified the $\mathrm{GaP}$ photocathode grown on Si substrate shows no change in the surface and composition from SEM and XPS.

\section{Conclusions}

In conclusion, we have demonstrated the hetero-integration of a high-quality GaP thin film on a silicon substrate by molecular beam epitaxy. Despite some performance penalty, the GaPon-Si photocathode, along with an earth-abundant $\mathrm{MoS}_{2}$ co-catalyst, shows great promise in 
reducing the cost of photocathodes based on GaP for hydrogen production. Additionally, the $\mathrm{Si} / \mathrm{GaP}-\mathrm{TiO}_{2}-\mathrm{MoS}_{2}$ photocathode exhibited a high stability for $3 \mathrm{~h}$ under continuous simulated solar light illumination at $\mathrm{HClO}_{4}(\mathrm{pH}$ ), exceeding that of the Pt-modified GaP photocathode. The high stability and cost-effective GaP photocathode grown on Si substrate without the use of noble metal HER catalysts are promising for low-cost, high efficiency, and stable PEC water splitting devices.

\section{Experimental Section}

$M B E$ growth: GaP thin films were directly grown on silicon substrates by a solid-source Veeco Gen 930 molecular beam epitaxy system. Phosphorus-doped Si (100) wafers with $4^{\circ}$ offcut to the [011] plane were used for the heteroepitaxy. Prior to epitaxy growth, the wafers were thermally annealed at $900{ }^{\circ} \mathrm{C}$ for five min to remove the silicon native oxide and form double atomic steps on silicon surface to avoid the formation of antiphase domains (APDs). After high temperature thermal treatment of the substrates, a $5 \mathrm{~nm} \mathrm{GaP}$ nucleation layer was deposited by migration enhanced epitaxy at a low growth temperature of $440{ }^{\circ} \mathrm{C}$. Figure $1 \mathrm{a}$ shows a cross-sectional transmission electron microscopy (TEM) image of the $\mathrm{Si} / \mathrm{GaP}$ interface. A sharp interface with no antiphase boundary was observed. Two layers of low temperature $\mathrm{GaP}$ were then grown at $440{ }^{\circ} \mathrm{C}, 500{ }^{\circ} \mathrm{C}$ for $20 \mathrm{~nm}$ and $100 \mathrm{~nm}$, respectively. Finally, a $4 \mu \mathrm{m}$ p-doped $\mathrm{GaP}$ layer was grown at $580{ }^{\circ} \mathrm{C}$.

Fabrication of GaP photocathodes: For single-crystalline reference GaP photocathode, Ti/Au $(50 / 100 \mathrm{~nm})$ metals were deposited on the back side of the GaP sample by thermal evaporation as a metal electrode to collecting holes generated from the photoelectrode. The contact metals were alloyed at $400{ }^{\circ} \mathrm{C}$ for $10 \mathrm{~s}$ by rapid thermal annealing to form a good ohmic contact. The GaP photocathode grown on Si substrate was fabricated by etching down the $\mathrm{GaP}$ top layer on the side and depositing $\mathrm{Ti} / \mathrm{Au}(50 / 100 \mathrm{~nm})$ metals on the exposed $\mathrm{GaP}$ bottom layer. Before the PEC experiments, the electrodes were attached by a copper wire using silver paste and covered by insulating epoxy.

Photoelectrochemical measurement: The photoelectrochemical performance of all p-GaP photocathodes was evaluated in a three-electrode configuration in $1 \mathrm{M}$ perchloric acid $\mathrm{HClO}_{4}$ ( $\mathrm{pH}$ 0) including the working electrodes, silver/silver chloride $(\mathrm{Ag} / \mathrm{AgCl})$ as reference electrode, and a Pt coil as counter electrode without any sacrificial agent. A 200W Xe arc lamp (66477-200HXF-R1 Mercury-Xenon) was used as a light source with AM 1.5 G filter to 
one sun based on the AM 1.5G standard. The illumination intensity was calibrated using a silicon reference cell with a power meter (Thorlabs, Model PM100A). The measured potentials vs. the $\mathrm{Ag} / \mathrm{AgCl}$ were converted to the reversible hydrogen electrode (RHE) scale using the following equation:

$$
\mathrm{V}_{\mathrm{RHE}}=\mathrm{V}_{\mathrm{Ag} / \mathrm{AgCI}}+0.059 \times \mathrm{PH}+\mathrm{V}_{\mathrm{Ag} / \mathrm{AgCI}}^{0}
$$

Where $\mathrm{V}_{\mathrm{Ag} / \mathrm{AgCI}}$ the potential is experimentally measured vs. $\mathrm{Ag} / \mathrm{AgCl}$ reference electrode, and $\mathrm{V}_{\mathrm{Ag} / \mathrm{AgCl}}^{0}$ is the standard potential of $\mathrm{Ag} / \mathrm{AgCl}$ at $25^{\circ} \mathrm{C}(0.1976 \mathrm{~V}$ vs. RHE). Before PEC experiments, the electrolyte was purged by Ar for $30 \mathrm{~min}$. All linear sweep voltammetry measurements with a scan rate of $50 \mathrm{mV} \mathrm{s}^{-1}$ was performed under both dark and illumination conditions using Ivium CompactStat. The incident photon-to-current conversion efficiency (IPCE) measurement at each wavelength for photocathodes was measured using the same three-electrode setup equipped with a monochromator at $-0.80 \mathrm{~V}$ versus (RHE).

Hydrogen measurements: Hydrogen was detected in the gas phase using a Clark electrode (Unisense, Denmark) while the photoelectrode was held at a constant potential and 1 sun illumination in a gas-tight photoelectrochemical (PEC) cell consisting of the $\mathrm{GaP}$ working electrode, a $\mathrm{Ag} / \mathrm{AgCl}$ (sat'd $\mathrm{KCl}$ ) reference electrode and a $\mathrm{Pt}$ mesh counter electrode immersed in $0.1 \mathrm{M} \mathrm{H}_{2} \mathrm{SO}_{4}$ (pH 1.1) (Supplementary Fig. S7). Prior to gas measurements the PEC cell was purged with nitrogen (99.999\% pure, BOC) such that the oxygen sensor (Unisense, Denmark) showed a sufficiently low voltage indicative of only trace amounts. Then the $\mathrm{N}_{2}$ flow was cut, the cell sealed and after 5 minutes the chronoamperometric measurement under illumination started. After the $\mathrm{H}_{2}$ measurement, a calibration of the Clark electrode was carried out injecting known volumes of $\mathrm{H}_{2}$ into the same $\mathrm{PEC}$ reactor using a gas-tight syringe. The Faradaic efficiency (FE) was calculated according to $\mathrm{FE}=\mathrm{nNF} / \mathrm{Q}$ where $\mathrm{n}$ is the number of moles $\mathrm{H}_{2}, \mathrm{~N}$ is the number of electrons in the reaction $(=2$ for proton reduction), $\mathrm{F}$ is the Faradaic constant $(=96485 \mathrm{C} / \mathrm{mol})$ and $\mathrm{Q}$ is the charge passed through the working electrode (calculated from the current produced in the chronoamperometry measurement).

Atomic layer deposition of $\mathrm{TiO}_{2}$ : Atomic layer deposition of amorphous $\mathrm{TiO}_{2}$ thin films on $\mathrm{Si} / \mathrm{GaP}$ substrate was obtained by a home built ALD system using titanium isopropoxide (TTIP) as metal precursor and water as precursor ${ }^{27}$. TTIP was kept at room temperature $\left(25^{\circ} \mathrm{C}\right.$ ) while water was kept at $5{ }^{\circ} \mathrm{C}$. The deposition temperature was maintained to $150{ }^{\circ} \mathrm{C}$. Each ALD cycle consisted of a $2 \mathrm{~s}$ TTIP pulse, a 1 min argon purge, then followed by a $2 \mathrm{~s}$ 
water pulse and a $3 \mathrm{~min}$ argon purge. The gas flow rate was set to 70 standard cubic centimetres per minute $(\mathrm{sccm})$. The growth rate of ALD process through this system was approximately $0.4 \AA$ A/cycle.

Atomic layer deposition of $\mathrm{MoS}_{2}$ : The $\mathrm{MoS}_{2}$ layer was also deposited by ALD system using $\mathrm{MoCl}_{5}$ and $\mathrm{H}_{2} \mathrm{~S}$ mixed gas (4 mol\%, with $\mathrm{N} 2$ gas) as molybdenum and sulfur precursor, respectively. $\mathrm{MoCl}_{5}$ was kept at $70^{\circ} \mathrm{C}$ and injected with $\mathrm{Ar}(50 \mathrm{sccm})$ carrier gas. $\mathrm{H}_{2} \mathrm{~S}$ mixed gas was injected with a flow rate of $30 \mathrm{sccm}$ without carrier gas. Each ALD cycle consisted of $0.2 \mathrm{~s} \mathrm{MoCl}_{5}$ pulse and $0.2 \mathrm{~s} \mathrm{H}_{2} \mathrm{~S}$ pulse separated by $15 \mathrm{~s}$ of Ar purge step. Deposition temperature was kept at $250{ }^{\circ} \mathrm{C}$ and the growth rate was approximately $0.6 \sim 0.7 \AA$ /cycle

Sputtering of platinum: Platinum catalysts were deposited using a sputter deposition system with a background pressure below $5 \times 10^{-8}$ Torr. Deposition conditions were as follows: power $75 \mathrm{~W}$, target voltage $436 \mathrm{~V}$, and 4 target current $0.15 \mathrm{~A}$. The growth rate was 4 $\mathrm{nm} / \min ^{1}$

Material characterization: For cross-sectional TEM imaging of the thick GaP structures on $\mathrm{Si}$, samples were prepared using mechanical polishing followed by ion-milling in a Fischione 1010 ion mill. An FEI Titan 80-300S TEM at 300kV, fitted with a CEOS image corrector, was used to perform the observations. The high-resolution scanning TEM (STEM) images of the surface protection layer and catalysts were obtained using a Hitachi HD2700 TEM operated at $200 \mathrm{kV}$ in bright field modes. Energy Dispersive X-ray Spectroscopy (EDS) data was acquired a Bruker Quantax system. The STEM sample was prepared by FEI FIB200 focused ion beam and thinned to electron transparency. Scanning electron microscopy (SEM) analysis was carried out using a Hitachi S-4800 SEM at 3kV accelerating voltage. The AFM images were acquired with a Vecco Dimension V Scanning Probe Microscope with tapping mode at atmospheric pressure with a $\mathrm{Si}$ cantilever with $10 \mathrm{~nm}$ of radius. X-ray Photoelectron Spectroscopy (XPS) measurements were performed with a Thermo monochromated aluminium k-alfa photoelectron spectrometer, using monochromic Al-Ka radiation (1486.7 $\mathrm{eV}$ ). Survey scans were collected in the range of 0-1300 eV. High resolution peaks were used for the principal peaks of $\mathrm{Ga}, \mathrm{P}, \mathrm{Ti}, \mathrm{O}, \mathrm{Mo}, \mathrm{S}$, and Pt. The area underneath these bands is an indication of the concentration of element within the region of analysis (spot size $400 \mu \mathrm{m}$ ). Data was analysed with CasaXPS software. 


\section{Conflict of Interest:}

The authors declare no conflict of interest.

\section{Acknowledgements}

We acknowledge support from King Abdulaziz City for Science and Technology, Riyadh, Saudi Arabia, EPSRC grant EP/P006973/1, the Ministry of Science, ICT \& Future Planning (MSIP) of Korea under contracts with NRF-20181A3A1A32055268, and the National Science Foundation of the US (EPSCoR Grant \#OIA-1457888). Mahdi Alqahtani gratefully acknowledge support and scholarship from King Abdulaziz City for Science and Technology, Riyadh, Saudi Arabia.

\section{Author contributions}

M.A. and J.W. conceived the idea. M.A. performed the PEC experiments and analysed the data. I. P. P. and S.S. performed XPS and related analysis. J.W. and H.L. performed the growth of the samples. M.B., Y.I.M., and G.J.S. carried out the STEM experiment for the GaP on Si sample. S.S. and J.W. analysed the STEM and EDX mapping. F.C. performed SEM and AFM. X.X. and C.B. performed $\mathrm{ALD} \mathrm{TiO}$ 2. E.K. and H.S. performed ALD deposition of $\mathrm{MoS}_{2}$. L.S. performed gas chromatography for $\mathrm{H}_{2}$ production and related analysis. M.A. and J.W wrote the manuscript. I. P. P. supervised M. A. All authors reviewed and commented on the manuscript.

\section{References}

1. $\quad$ M. Gratzel, Nature, 2001, 414, 338-344.

2. A. J. Bard, Science, 1980, 207, 139-144.

3. Y. Tachibana, L. Vayssieres and J. R. Durrant, Nature Photonics, 2012, 6, 511-518.

4. M. G. Walter, E. L. Warren, J. R. McKone, S. W. Boettcher, Q. Mi, E. A. Santori and N. S. Lewis, Chem Rev, 2010, 110, 6446-6473.

5. B. Seger, I. E. Castelli, P. C. K. Vesborg, K. W. Jacobsen, O. Hansen and I. Chorkendorff, Energy \& Environmental Science, 2014, 7, 2397-2413.

6. N. S. Lewis, Science, 2016, 351, aad1920.

7. M. R. Shaner, H. A. Atwater, N. S. Lewis and E. W. McFarland, Energy \& Environmental Science, 2016, 9, 2354-2371.

8. R. C. Armstrong, C. Wolfram, K. P. de Jong, R. Gross, N. S. Lewis, B. Boardman, A. J. Ragauskas, K. Ehrhardt-Martinez, G. Crabtree and M. V. Ramana, Nat Energy, 2016, 1, 15020.

9. K. Iwashina and A. Kudo, J Am Chem Soc, 2011, 133, 13272-13275. 
10. A. Fujishima and K. Honda, Nature, 1972, 238, 37-+.

11. S. Hu, M. R. Shaner, J. A. Beardslee, M. Lichterman, B. S. Brunschwig and N. S. Lewis, Science, 2014, 344, 1005-1009.

12. J. Gu, Y. Yan, J. L. Young, K. X. Steirer, N. R. Neale and J. A. Turner, Nat Mater, 2016, 15, 456-460.

13. J. Wu, Y. Li, J. Kubota, K. Domen, M. Aagesen, T. Ward, A. Sanchez, R. Beanland, Y. Zhang, M. Tang, S. Hatch, A. Seeds and H. Liu, Nano Lett, 2014, 14, 2013-2018.

14. A. Standing, S. Assali, L. Gao, M. A. Verheijen, D. van Dam, Y. Cui, P. H. Notten, J. E. Haverkort and E. P. Bakkers, Nat Commun, 2015, 6, 7824.

15. P. Guilleme, M. Vallet, J. Stodolna, A. Ponchet, C. Cornet, A. Letoublon, P. Feron, O. Durand, Y. Leger and Y. Dumeige, Opt Express, 2016, 24, 14608-14617.

16. N. C. Strandwitz, D. B. Turner-Evans, A. C. Tamboli, C. T. Chen, H. A. Atwater and N. S. Lewis, Advanced Energy Materials, 2012, 2, 1109-1116.

17. M. Malizia, B. Seger, I. Chorkendorff and P. C. K. Vesborg, J. Mater. Chem. A, 2014, 2, 6847-6853.

18. A. M. Beiler, D. Khusnutdinova, S. I. Jacob and G. F. Moore, ACS Appl Mater Interfaces, 2016, 8, 10038-10047.

19. D. Khusnutdinova, A. M. Beiler, B. L. Wadsworth, S. I. Jacob and G. F. Moore, Chem Sci, 2017, 8, 253-259.

20. H. Emmer, C. T. Chen, R. Saive, D. Friedrich, Y. Horie, A. Arbabi, A. Faraon and H. A. Atwater, Sci Rep, 2017, 7, 4643.

21. D. S. Bae, B. Vesborg, P. C. Hansen, O. Chorkendorff, I., Chem Soc Rev, 2017, 46, 1933-1954.

22. A. Paracchino, V. Laporte, K. Sivula, M. Gratzel and E. Thimsen, Nat Mater, 2011, 10, 456-461.

23. Y. W. Chen, J. D. Prange, S. Duhnen, Y. Park, M. Gunji, C. E. Chidsey and P. C. McIntyre, Nat Mater, 2011, 10, 539-544.

24. B. Seger, T. Pedersen, A. B. Laursen, P. C. Vesborg, O. Hansen and I. Chorkendorff, $J$ Am Chem Soc, 2013, 135, 1057-1064.

25. D. Merki and X. Hu, Energy \& Environmental Science, 2011, 4, 3878.

26. S. Lee, A. R. Bielinski, E. Fahrenkrug, N. P. Dasgupta and S. Maldonado, ACS Appl Mater Interfaces, 2016, 8, 16178-16185.

27. R. L. Wilson, C. E. Simion, C. S. Blackman, C. J. Carmalt, A. Stanoiu, F. Di Maggio and J. A. Covington, Sensors (Basel), 2018, 18. 

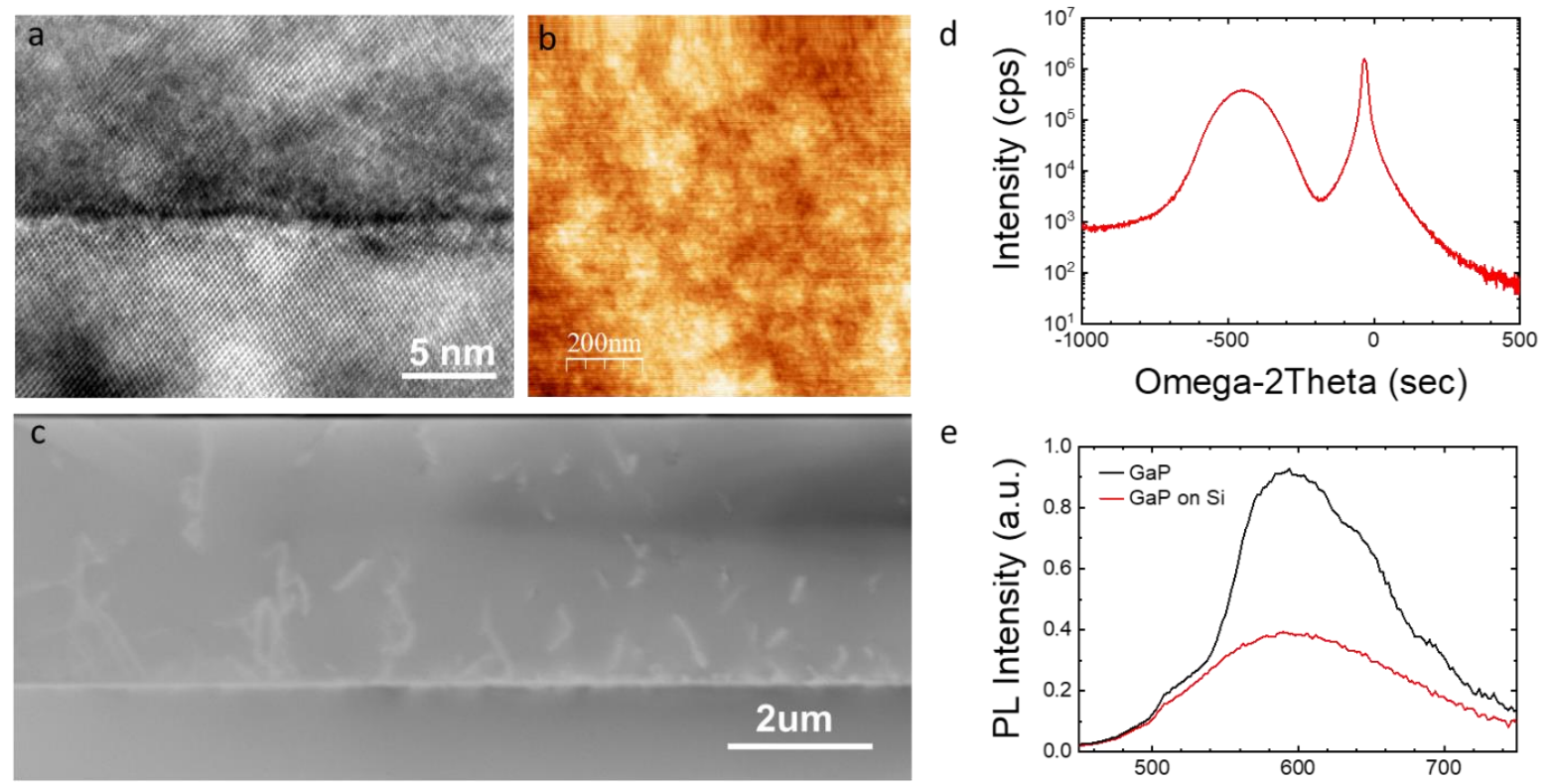

e

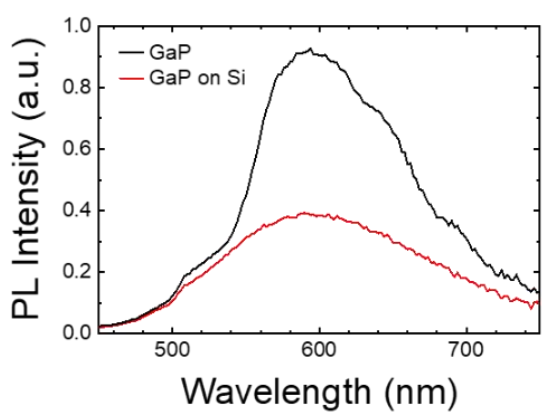

Figure 1. a. Cross-sectional HRTEM image of the Si/GaP interface. The scale bar is $5 \mathrm{~nm}$. b. Atomic force microscopy image shows very low surface roughness. The scale bar is $200 \mathrm{~nm}$ and the Z-scale is $3 \mathrm{~nm}$. c. High-angle annular dark-field (HAADF) STEM image of the GaP epilayer grown on a Si substrate. The scale bar is $2 \mu \mathrm{m}$. d. X-ray diffraction of the GaP film grown on a Si substrate. e. Photoluminescence spectra of a $\mathrm{GaP}$ wafer (black curve) and the $\mathrm{GaP}$ film (red curve) grown directly on a Si substrate at room temperature. 
Figure 2. a. Structural, chemical profiling of the Si/GaP-TiO2-Pt photocathode, and PEC measurements. a. Cross-sectional STEM image $\mathrm{Si} / \mathrm{GaP}_{-}-\mathrm{TiO}_{2}-\mathrm{Pt}$ photocathode (scale bar 20 nm). b. Energy Dispersive X-ray Spectroscopy (EDS) mapping shows the individual layer thickness associated with the Ti, O, Ga, P, and Pt elements (scale bar $20 \mathrm{~nm}$ ). c. Photocurrent density-potential $(J-V)$ curves (scan rate is $50 \mathrm{mV} \mathrm{s}^{-1}$ ) of $\mathrm{GaP}_{-} \mathrm{TiO}_{2}-\mathrm{Pt}$ (red line) and $\mathrm{Si} / \mathrm{GaP}-$ $\mathrm{TiO}_{2}-\mathrm{Pt}$ (blue line) photocathodes in $1 \mathrm{M} \mathrm{HClO}_{4}$ under one sun illumination. d. Incident photon-to-current conversion efficiency (IPCE) of $\mathrm{GaP}_{-}-\mathrm{TiO}_{2}-\mathrm{Pt}$ (red line) and $\mathrm{Si} / \mathrm{GaP}^{-\mathrm{TiO}_{2}-\mathrm{Pt}}$ (blue line) photocathodes in $1 \mathrm{M} \mathrm{HClO}_{4}$ at $-0.8 \mathrm{~V}$ versus RHE. 
Figure 3. Structural, chemical profiling of the $\mathrm{Si} / \mathrm{GaP}-\mathrm{TiO}_{2}-\mathrm{MoS} 2$ photocathode, and PEC measurements. a. Cross-sectional STEM image $\mathrm{Si} / \mathrm{GaP}-\mathrm{TiO}_{2}-\mathrm{MoS}_{2}$ photocathode (scale bar $20 \mathrm{~nm}$ ). b. EDS line profiling coupled with spectral component matching and the mapping shows the individual layer thickness associated with the $\mathrm{Ti}, \mathrm{O}, \mathrm{Ga}, \mathrm{P}, \mathrm{Mo}$, and $\mathrm{S}$ elements (scale bar $20 \mathrm{~nm}$ ). c. Photocurrent density-potential $(J-V)$ curves (scan rate is 50 $\mathrm{mV} \mathrm{s}^{-1}$ ) of $\mathrm{GaP}_{-} \mathrm{TiO}_{2}-\mathrm{Pt}$ (red line), $\mathrm{Si} / \mathrm{GaP}-\mathrm{TiO}_{2}-\mathrm{Pt}$ (blue line), $\mathrm{Si} / \mathrm{GaP}-\mathrm{TiO}_{2}-\mathrm{MoS}_{2}$ (green line), and $\mathrm{GaP}_{-} \mathrm{TiO}_{2}-\mathrm{MoS}_{2}$ (black line) photocathodes in $1 \mathrm{M} \mathrm{HClO}_{4}$ under one sun illumination. d. Incident photon-to-current conversion efficiency (IPCE) of $\mathrm{GaP}_{-} \mathrm{TiO}_{2}-\mathrm{Pt}$ (red line), $\mathrm{Si} / \mathrm{GaP}_{-} \mathrm{TiO}_{2}-\mathrm{Pt}$ (blue line), $\mathrm{Si} / \mathrm{GaP}-\mathrm{TiO}_{2}-\mathrm{MoS}_{2}$ (green line), and $\mathrm{GaP}-\mathrm{TiO}_{2}-\mathrm{MoS}_{2}$ (black line) photocathodes in $1 \mathrm{M} \mathrm{HClO}_{4}$ at $-0.8 \mathrm{~V}$ versus RHE. Faradaic efficiency of $\mathrm{H}_{2}$ production measured with a Clark $\mathrm{H}_{2}$ sensor in a gas-tight 3-electrode photoelectrochemical cell under illumination and constant potential. e. FE of the $\mathrm{Si} / \mathrm{GaP}-\mathrm{TiO}_{2}-\mathrm{MoS}_{2}$ photoelectrode held at $0.39 \mathrm{~V}$ vs. RHE. f. FE of the $\mathrm{GaP}_{-} \mathrm{TiO}_{2}-\mathrm{Pt}$ photoelectrode held at $-0.09 \mathrm{~V}$ vs. RHE. 
Figure 4 a. Photoelectrochemical stability measurements of a various GaP photocathodes for 30 min photocurrent density-time $(J-t)$ plots held at $0 \mathrm{~V}$ versus $\mathrm{RHE}$ in in $1 \mathrm{M} \mathrm{HClO}_{4}$ under one sun illumination. b. Photoelectrochemical long stability measurements of a various $\mathrm{GaP}$ photocathodes for $3 \mathrm{~h}$ held at $0 \mathrm{~V}$ versus RHE in $1 \mathrm{M} \mathrm{HClO}_{4}$ under 1 sun illumination. SEM images of the photoelectrodes after reliability test (> 3h): c. $\mathrm{Si} / \mathrm{GaP}-\mathrm{TiO}_{2}-\mathrm{MoS}_{2}$ and d.

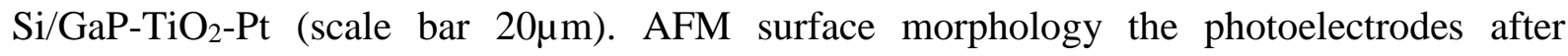

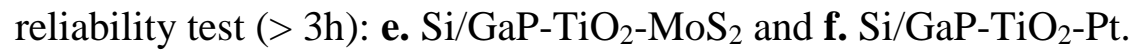
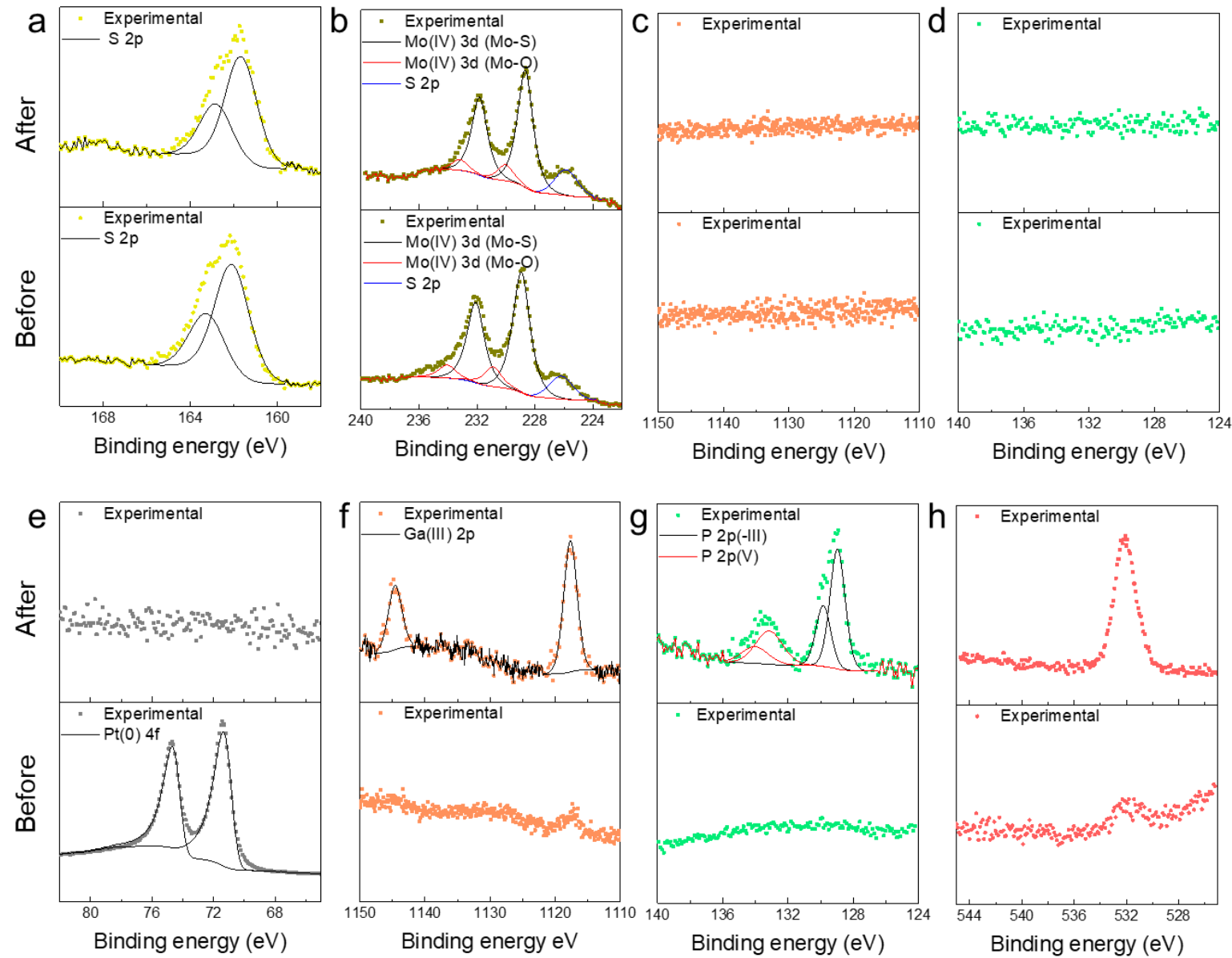

Figure 5. a-d. XPS measurements of the $\mathrm{Si} / \mathrm{GaP}-\mathrm{TiO}_{2}-\mathrm{MoS}_{2}$ photocathode before (bottom column) and after (top column) the photoelectrochemical stability measurement. Before testing, the structure contains Mo $3 \mathrm{~d}$ and $2 \mathrm{p}$ corresponding to $\mathrm{MoS}_{2}$. There is no presence of $\mathrm{Ga}$ or P peaks before testing. After testing, the composition and chemical state remain very similar. There is still no presence of $\mathrm{Ga}$ and $\mathrm{P}$ peaks after testing, as shown in $\mathbf{c}$ and $\mathbf{d}$. e-h. XPS measurements of the $\mathrm{Si} / \mathrm{GaP}-\mathrm{TiO}_{2}-\mathrm{Pt}$ photocathode before (bottom column) and after (top column) the photoelectrochemical stability measurement. Before testing, the surface 
contains $\mathrm{Pt} 4 \mathrm{f}$, corresponding to Pt. There is no presence of $\mathrm{Ga}$ and $\mathrm{P}$ peaks before testing. After testing, Pt peak is no longer present, and this indicates the complete removal of $\mathrm{Pt}$ catalyst. Ga and P peaks clear appear after testing, as shown in $\mathbf{f}$ and $\mathbf{g}$. A peak corresponding to $\mathrm{O} 1 \mathrm{~s}$ also becomes more dominant but no Ti peak remains observable after testing, confirming the removal of the $\mathrm{Pt}$ catalyst layer and $\mathrm{TiO}_{2}$ protection layer.

\section{Supporting Information}

\section{Heteroepitaxy of GaP on Silicon for Efficient and Cost-Effective Photoelectrochemical Water Splitting}

Mahdi Alqahtani ${ }^{1,2^{*}}$, Sanjayan Sathasivam ${ }^{3}$, Fan Cui $^{1}$, Ludmilla Steier ${ }^{4}$, Xueming Xia ${ }^{3}$, Chris Blackman $^{3}$, Eunsoo Kim ${ }^{5}$, Hyunjung Shin ${ }^{6}$, Mourad Benamara ${ }^{6}$, Yuriy I. Mazur $^{6}$, Gregory J. Salamo ${ }^{6}$, Ivan P. Parkin ${ }^{3}$, Huiyun Liu ${ }^{1}$, and Jiang $W u^{1,7^{*}}$

${ }^{1}$ Department of Electronic and Electrical Engineering, University College London, London WC1E 7JE, United Kingdom.

${ }^{2}$ King Abdulaziz City for Science and Technology (KACST), Riyadh 12371, Saudi Arabia ${ }^{3}$ Department of Chemistry, University College London, London WC1H 0AJ, United Kingdom

${ }^{4}$ Department of Chemistry, Imperial College London, London SW7 2AZ, United Kingdom ${ }^{5}$ Department of Energy Science, Sungkyunkwan University, Seoul 440-746 South Korea ${ }^{6}$ Institute for Nanoscience and Engineering, University of Arkansas, Fayetteville, AR 72701, USA

${ }^{7}$ Institute of Fundamental and Frontier Sciences, University of Electronic Science and Technology of China, Chengdu 610054, China 


\section{Table of Contents}

Supplementary Information Figure S1. Atomic Force Microscopy (AFM) images of the $\mathrm{GaP}$ thin film directly grown on a Si substrate.

Supplementary Information Figure S2. AFM surface topography and bright field TEM image for the $\mathrm{Si} / \mathrm{GaP}$ structure, showing a small number of threading dislocation, terminating at the surface.

Supplementary Information Figure S3. Fitting of the photoluminescence spectrum of the $\mathrm{Si} / \mathrm{GaP}$ film.

Supplementary Information Figure S4. The cross-sectional STEM images of the Si/GaP$\mathrm{TiO}_{2}-\mathrm{Pt}$ structure at different magnifications.

Supplementary Information Figure S5. STEM EDS line profiling of the $\mathrm{Si} / \mathrm{GaP}-\mathrm{TiO}_{2}-\mathrm{Pt}$ structure.

Supplementary Information Figure S6. The cross-sectional STEM images of the Si/GaP$\mathrm{TiO}_{2}-\mathrm{MoS}_{2}$ structure at different magnifications.

Supplementary Information Figure S7. STEM EDS line profiling of the Si/GaP-TiO $2-\mathrm{MoS}_{2}$ structure.

Supplementary Information Figure S8. $\mathrm{H}_{2}$ production for a gas-tight 3-electrode photoelectrochemical cell using the $\mathrm{Si} / \mathrm{GaP}-\mathrm{TiO}_{2}-\mathrm{Pt}$ photoelectrode.

Supplementary Information Figure S9. $\mathrm{H}_{2}$ production for a gas-tight 3-electrode photoelectrochemical cell using the $\mathrm{GaP}_{-} \mathrm{TiO}_{2}-\mathrm{Pt}$ photoelectrode.

Supplementary Information Figure S10. Faradaic efficiency measurements for $\mathrm{H}_{2}$ production.

Supplementary Information Figure S11. The experimental setup used for the photoelectrochemical measurements.

Supplementary Information Figure S12. Magnified SEM images of the photocathode surface after reliability test.

Supplementary Information Figure S13. AFM surface morphology the photoelectrodes after reliability test. 

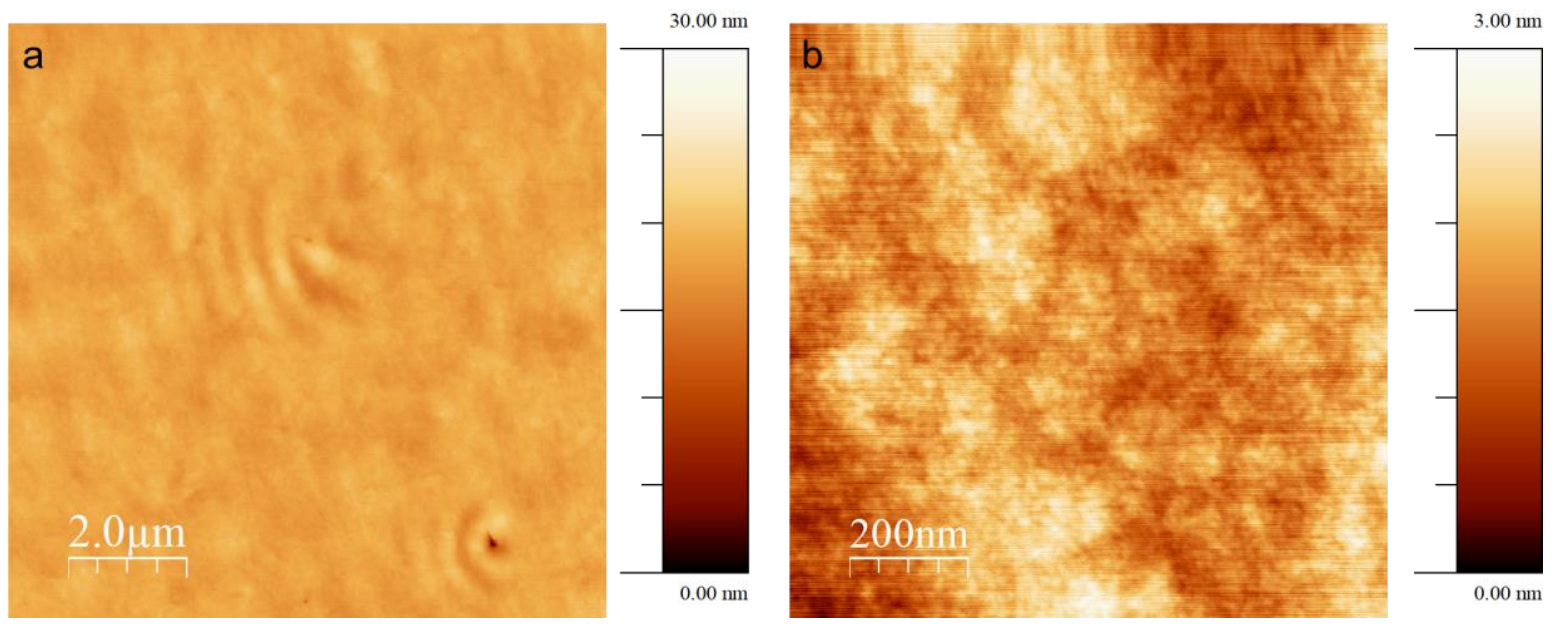

Supplementary Information Figure S1. Atomic Force Microscopy (AFM) images of the GaP thin film directly grown on a Si substrate: a. $10 \times 10 \mu \mathrm{m}^{2}$ and b. $1 \times 1 \mu^{2}$. The z-scale is $30 \mathrm{~nm}$ and $3 \mathrm{~nm}$ for the AFM images in (a) and (b) respectively. The root mean square roughness measured from the AFM images in (a) and (b) are $0.8 \mathrm{~nm}$ and $0.39 \mathrm{~nm}$, respectively. 


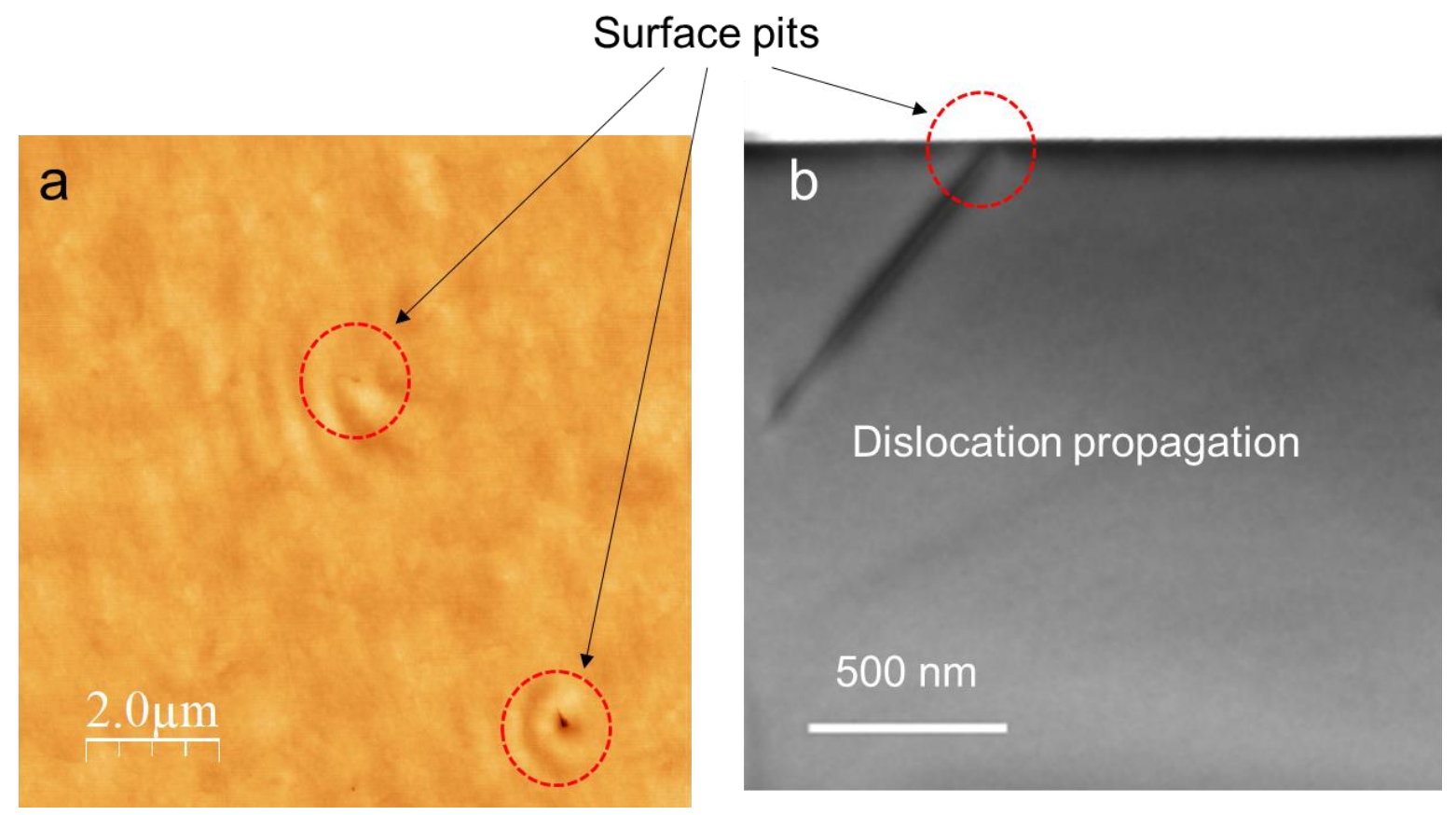

Supplementary Information Figure S2. a. AFM surface topography and b. bright field TEM image for the $\mathrm{Si} / \mathrm{GaP}$ structure, showing a small number of threading dislocations terminating at the surface. Most of the dislocations are annihilated in the epilayer, but some of the threading dislocations propagate towards the surface and are terminated at the surface pits. The density of dislocations propagating from the interface is very similar to the density throughout the entire structure. The atomic force microscopy image over the $10 \mu \mathrm{m} \times 10 \mu \mathrm{m}$ scan region gives a low density of threading dislocation of the order of $2 \times 10^{6} \mathrm{~cm}^{-2}$, which is in agreement with the TEM and XRD measurements. 


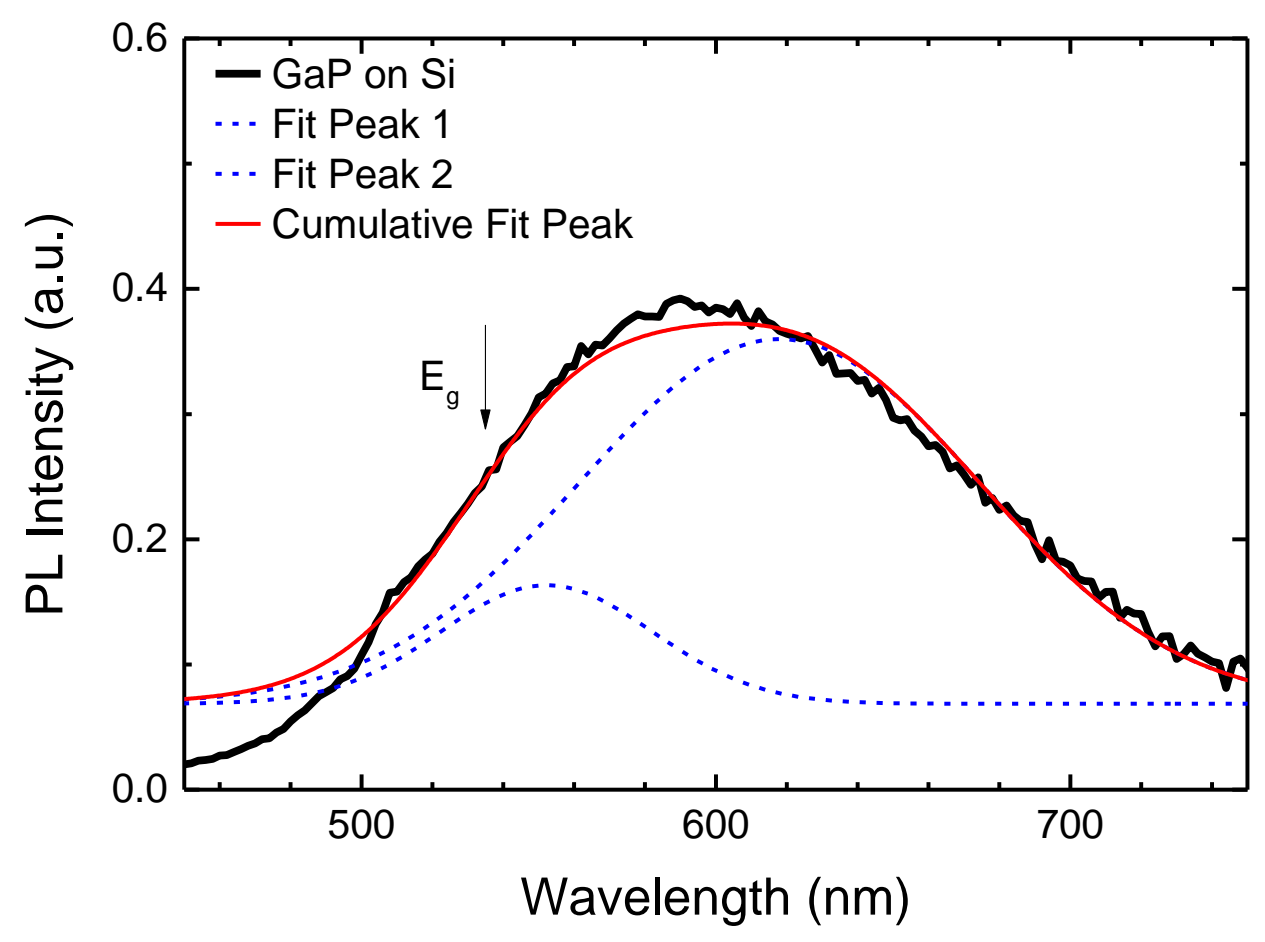

Supplementary Information Figure S3. Fitting of the photoluminescence spectrum of the $\mathrm{Si} / \mathrm{GaP}$ film. The peak 1 at around $550 \mathrm{~nm}$ corresponds to the bandgap of GaP. 


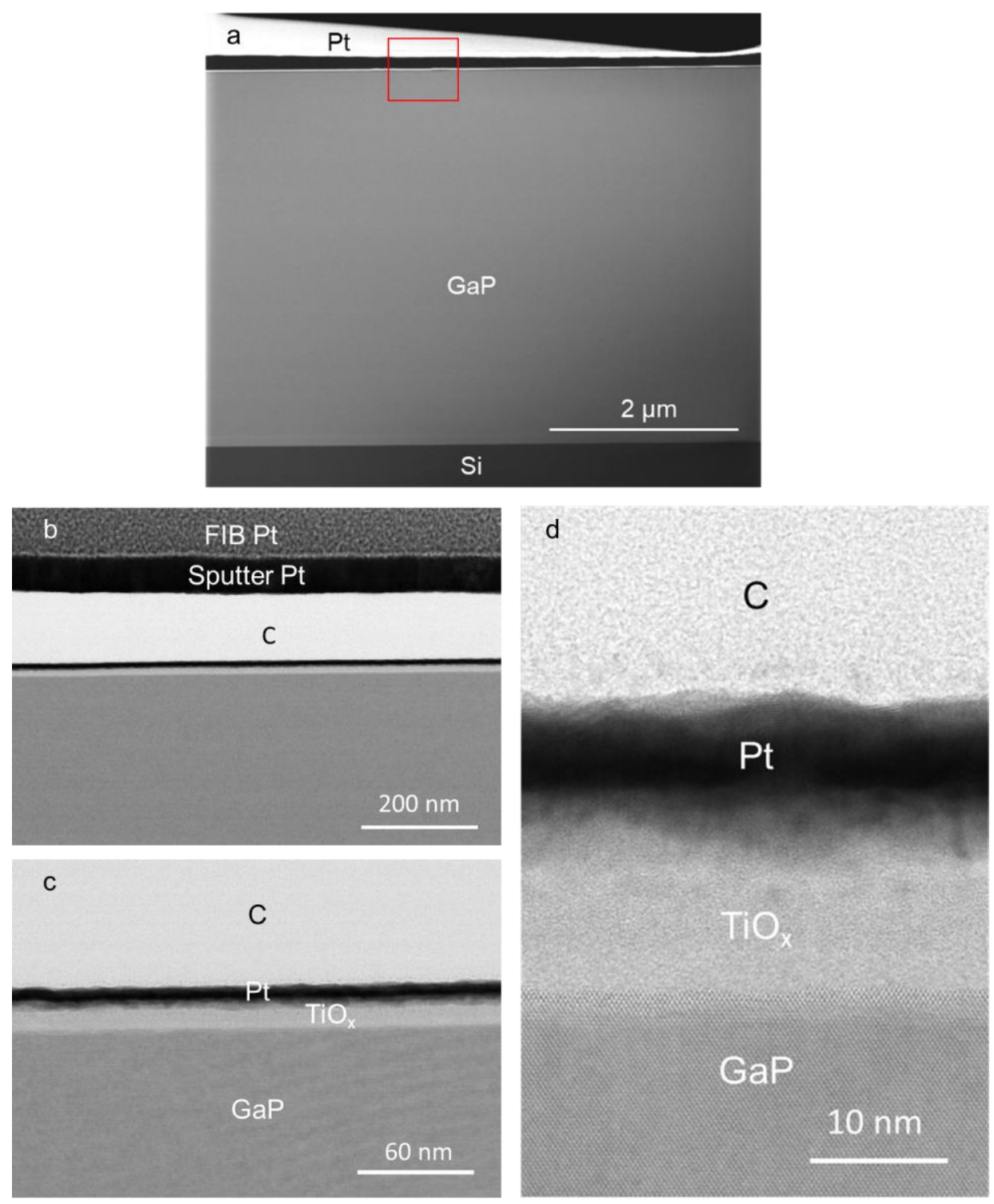

Supplementary Information Figure S4. a. The cross-sectional TEM images of the entire $\mathrm{Si} / \mathrm{GaP}-\mathrm{TiO}_{2}-\mathrm{Pt}$ structure. (b-d). Transmitted electron STEM images of the ALD deposited $\mathrm{TiO}_{2}$ protective layer and $\mathrm{Pt}$ catalyst layer at different magnifications. FIB Pt, sputtered $\mathrm{Pt}$ and $\mathrm{C}$ are from sample preparation. $\mathrm{C}$ and/or Pt protective coatings were applied prior to FIB milling. 
Supplementary Information Figure S5. STEM EDS line profiling coupled with spectral component matching showing the individual layer thickness for $\mathrm{TiO}_{\mathrm{x}}$ and $\mathrm{Pt}$. The $\mathrm{Y}$-axis is un-calibrated element intensity. Note that there is some inter-diffusion in the $\mathrm{GaP}_{\mathrm{TiO}} \mathrm{x}$ interface and $\mathrm{TiO}_{\mathrm{x}} / \mathrm{Pt}$ interface. The inset is the STEM image where the EDS line profiling was taken. 

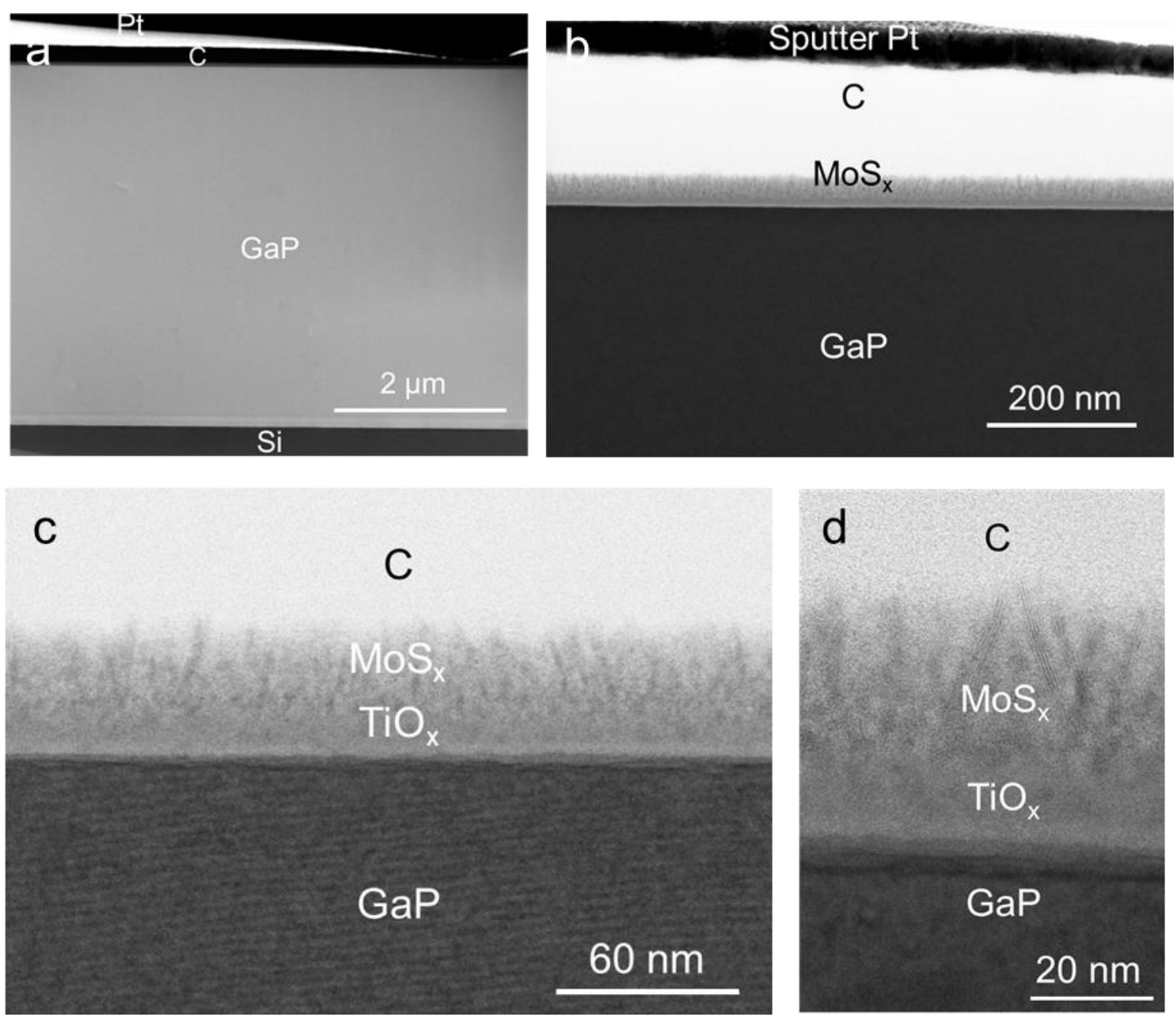

Supplementary Information Figure S6. a. The cross-sectional high-angle annular darkfield (HAADF) STEM images of the entire $\mathrm{Si} / \mathrm{GaP}-\mathrm{TiO}_{2}-\mathrm{MoS}_{2}$ structure. b-d. Transmitted electron STEM images of the ALD deposited $\mathrm{TiO}_{2}$ protective layer and $\mathrm{MoS}_{2}$ catalyst layer at different magnifications. Sputtered $\mathrm{Pt}$ and $\mathrm{C}$ are from sample preparation. $\mathrm{C}$ and/or $\mathrm{Pt}$ protective coatings were applied prior to FIB milling. 


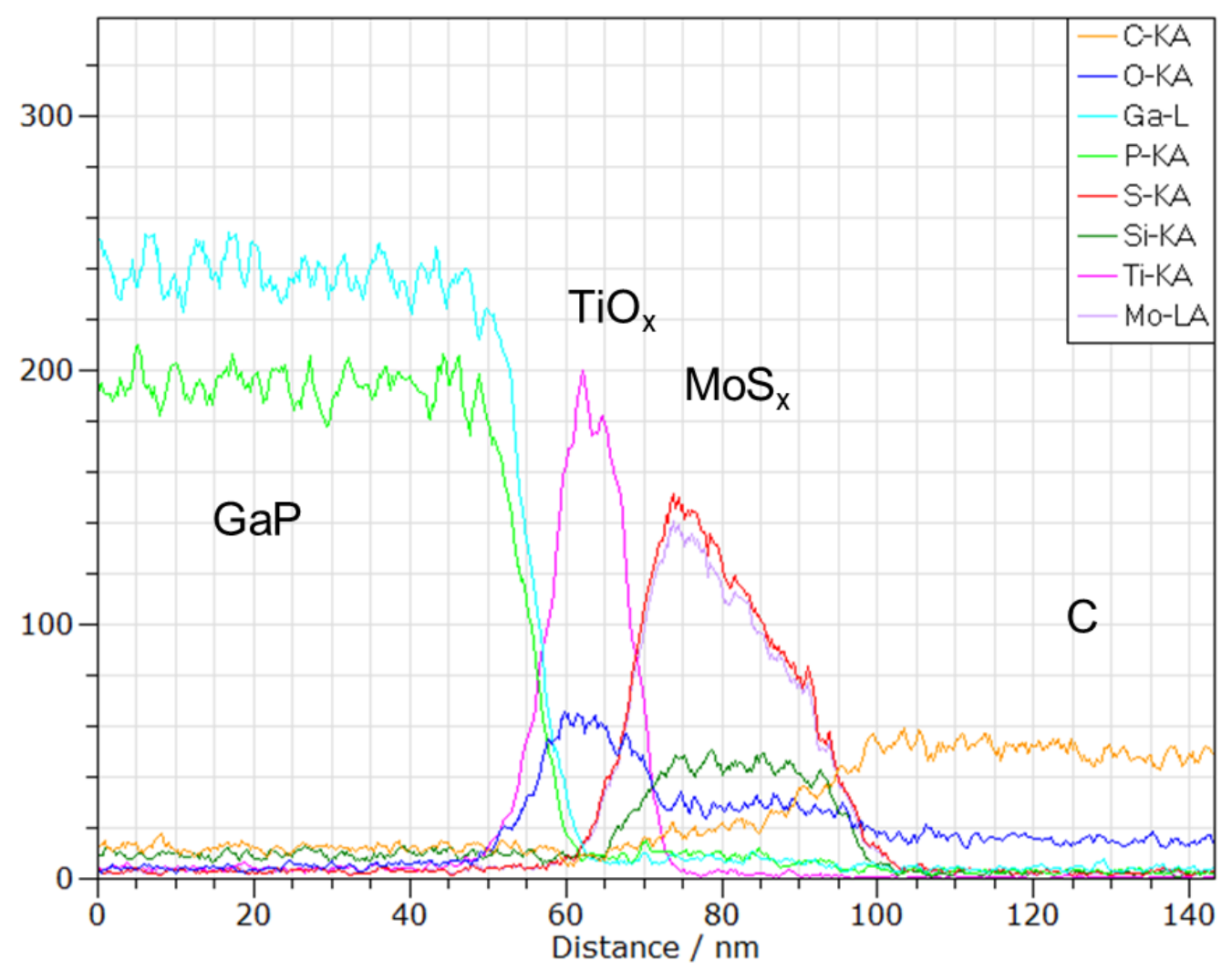

$\mathrm{GaP}$

$\mathrm{TiO}_{\mathrm{x}} \mathrm{MoS}_{\mathrm{x}}$

C

Supplementary Information Figure S7. STEM EDS line profiling coupled with spectral component matching showing the individual layer thickness for $\mathrm{TiO}_{\mathrm{x}}$ and $\mathrm{MoS}_{\mathrm{x}}$. The $\mathrm{Y}$-axis is un-calibrated element intensity. The inset is the STEM image where the EDS line profiling was taken. 


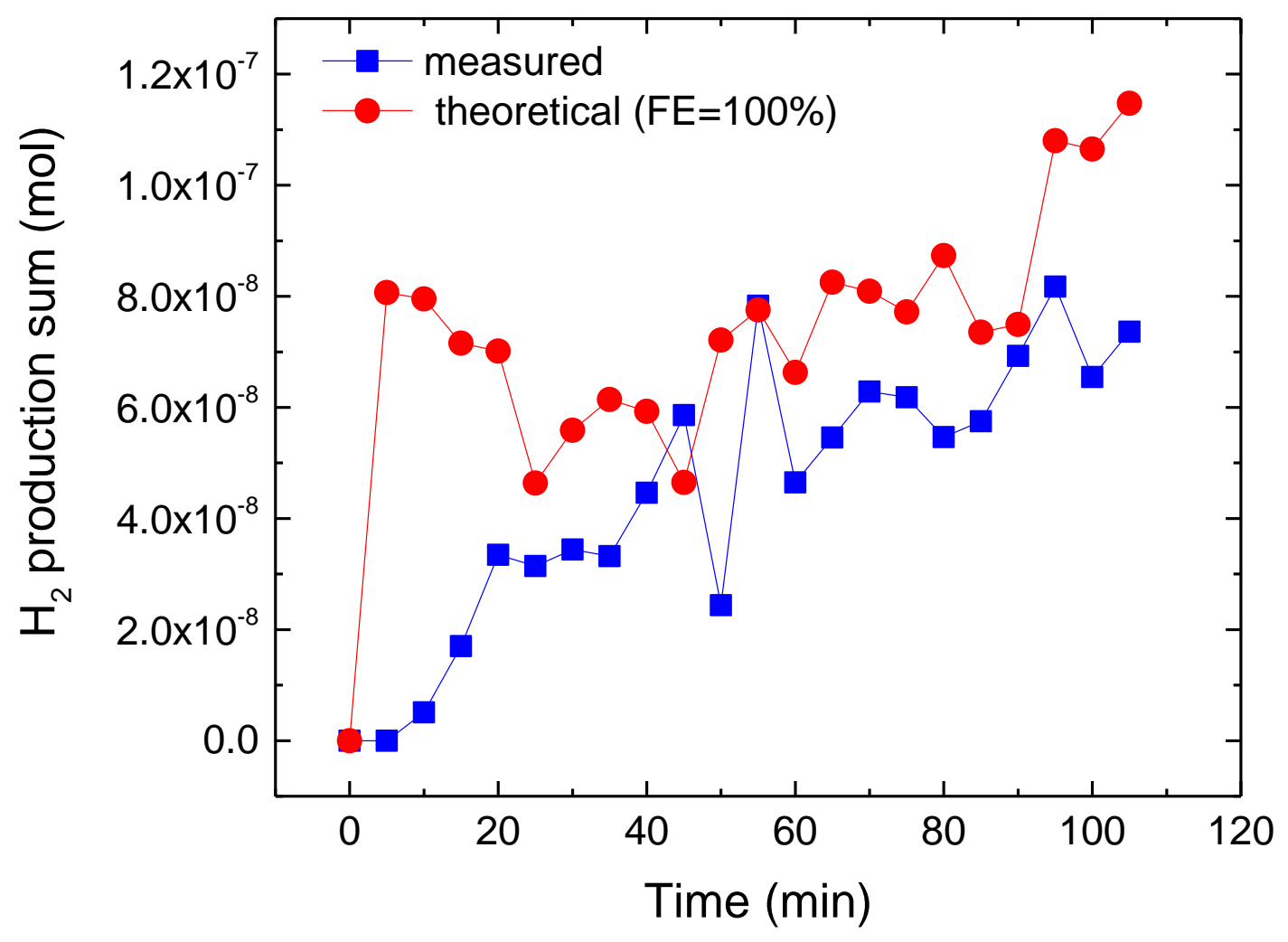

Supplementary Information Figure S8. $\mathrm{H}_{2}$ production measured with a Clark $\mathrm{H}_{2}$ sensor in a gas-tight 3-electrode photoelectrochemical cell under illumination and a constant potential at $0.39 \mathrm{~V}$ vs. RHE. The photocathode is the the $\mathrm{Si} / \mathrm{GaP}-\mathrm{TiO}_{2}-\mathrm{MoS}_{2}$ photoelectrode. The red dots indicate the calculated $\mathrm{H}_{2}$ production by assuming Faradaic efficiency of $100 \%$. 


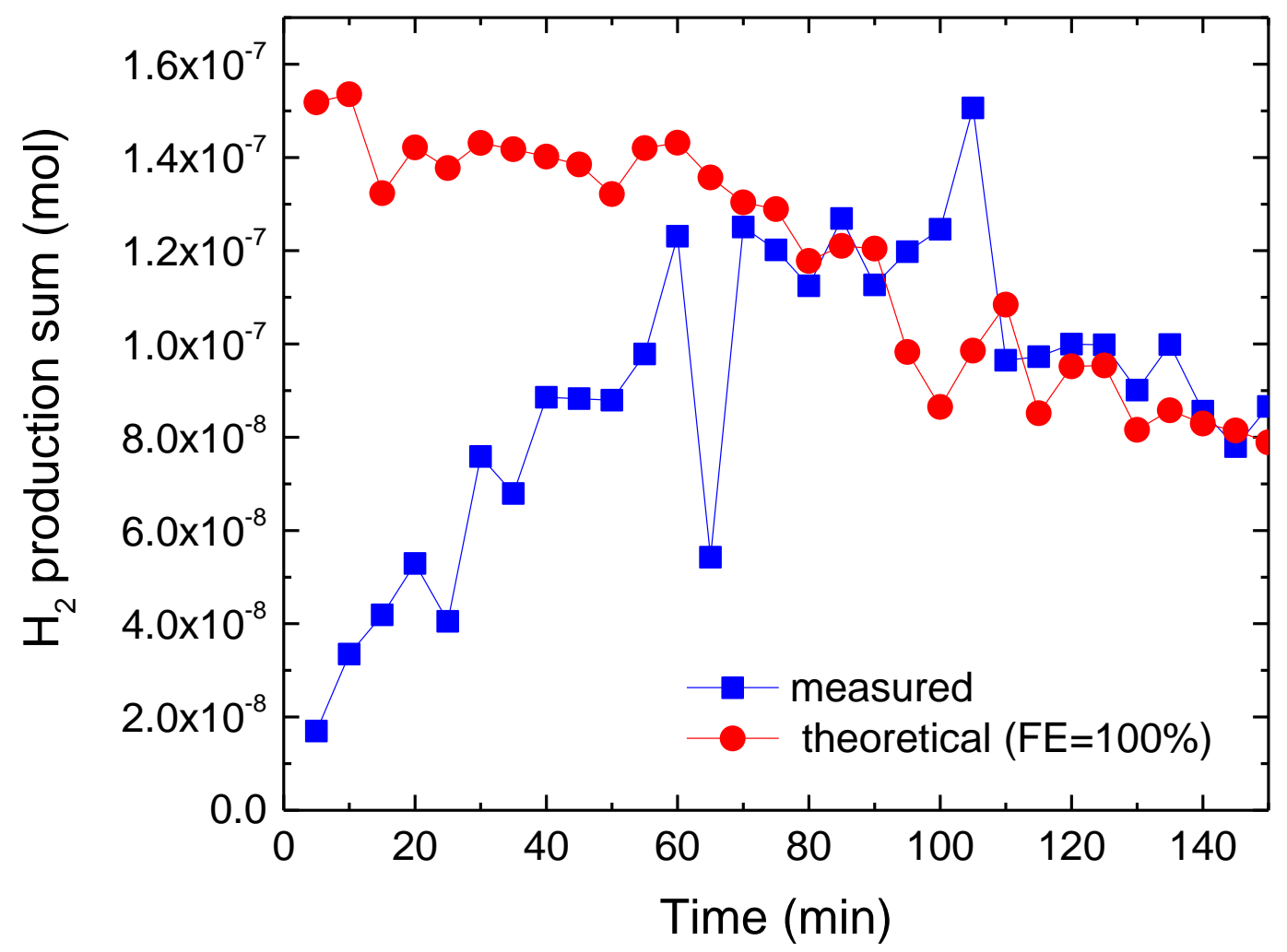

Supplementary Information Figure S9. $\mathrm{H}_{2}$ production measured with a Clark $\mathrm{H}_{2}$ sensor in a gas-tight 3-electrode photoelectrochemical cell under illumination and constant potential at -

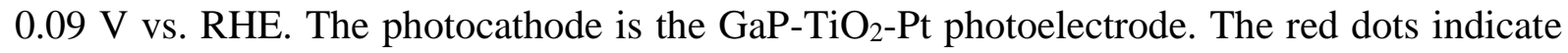
the calculated $\mathrm{H}_{2}$ production by assuming Faradaic efficiency of $100 \%$. 

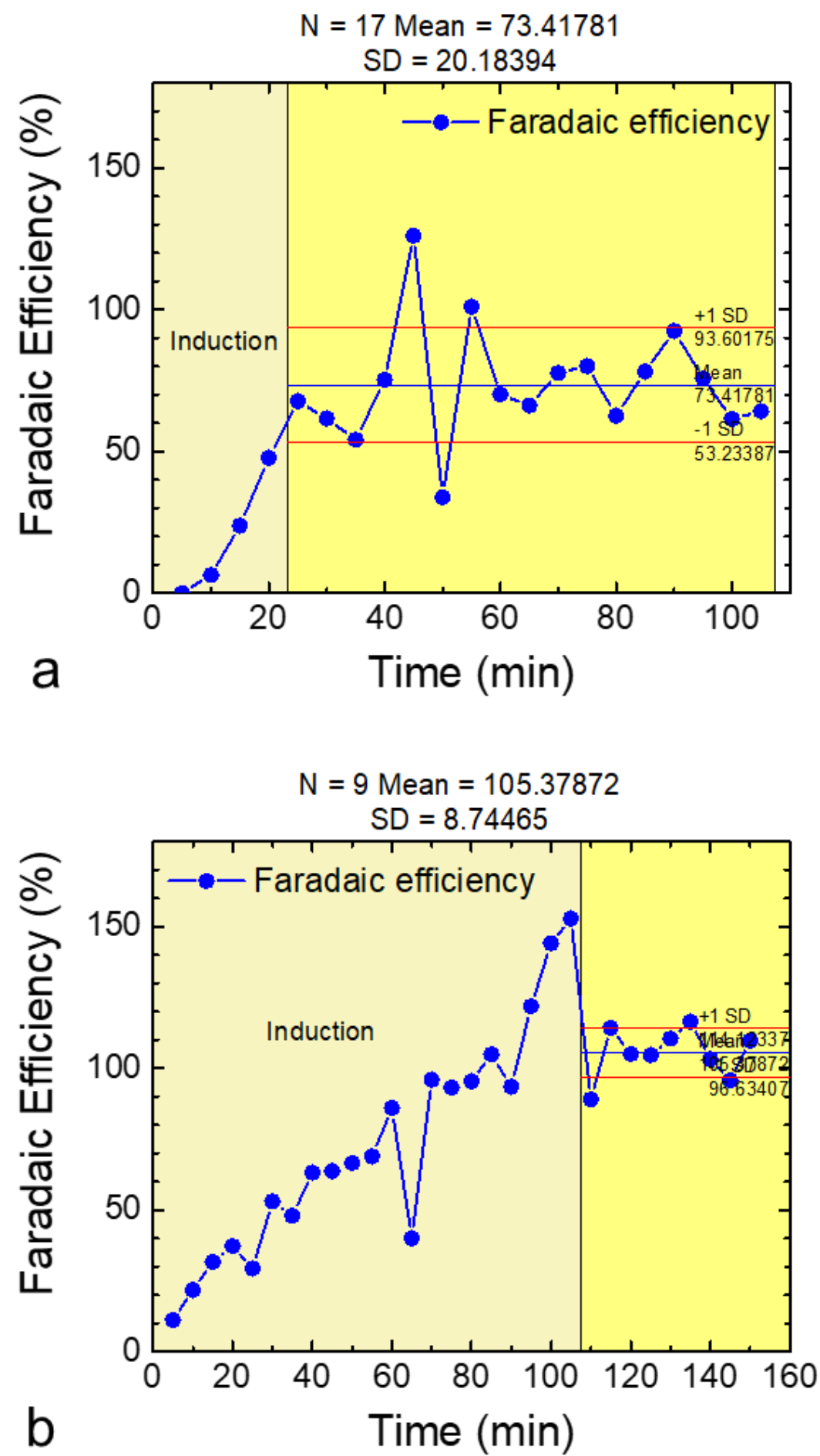

Supplementary Information Figure S10. Faradaic efficiency of $\mathrm{H}_{2}$ production measured with a Clark $\mathrm{H}_{2}$ sensor in a gas-tight 3-electrode photoelectrochemical cell under illumination and constant potential. a) $\mathrm{FE}$ of the $\mathrm{Si} / \mathrm{GaP}-\mathrm{TiO}_{2}-\mathrm{MoS}_{2}$ photoelectrode held at $-0.39 \mathrm{~V}$ vs.

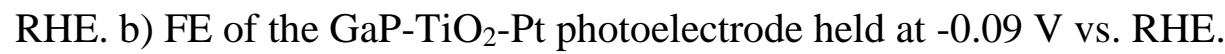




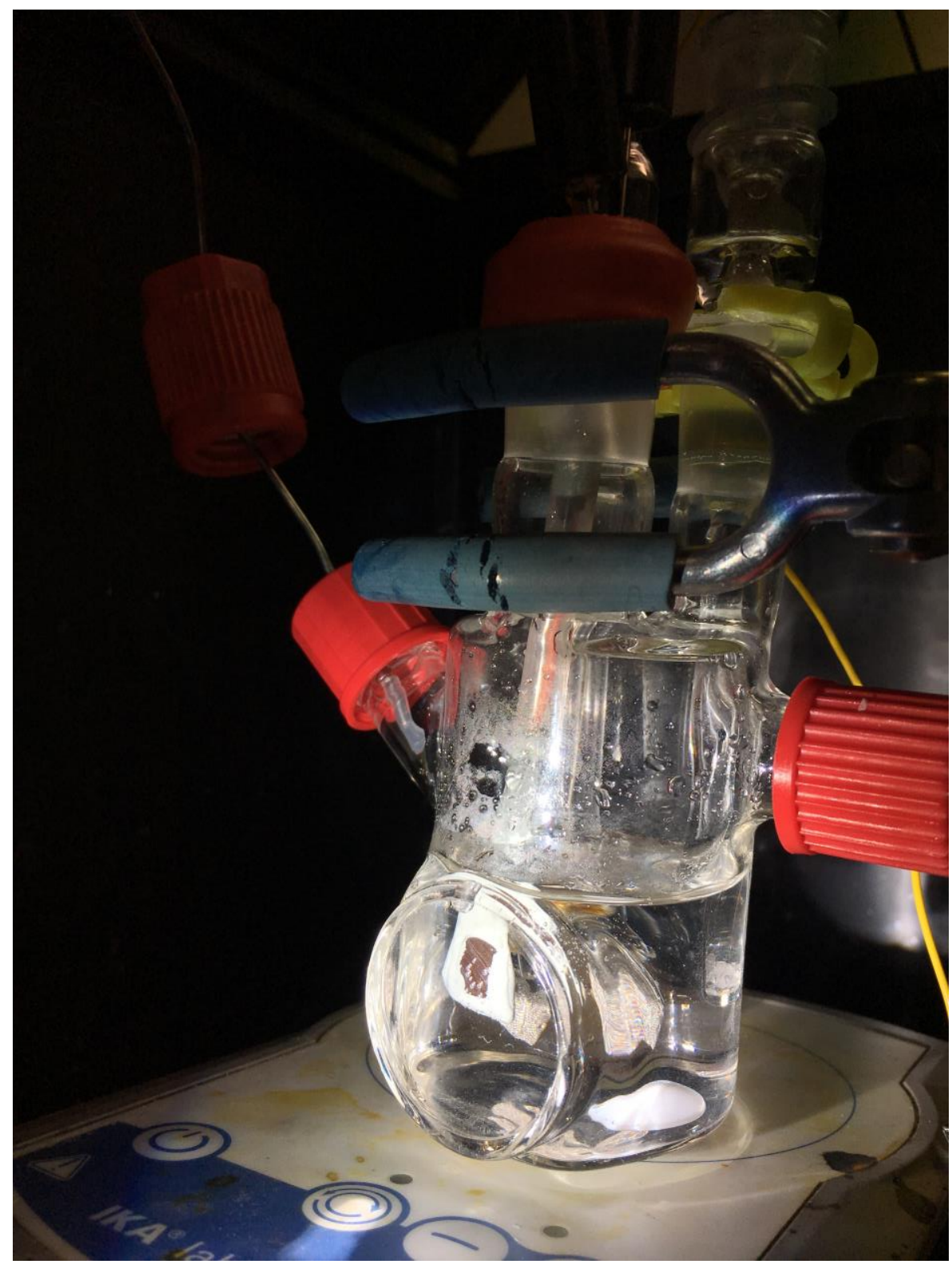

Supplementary Information Figure S11. The experimental setup used for the photoelectrochemical measurements which consists of the working electrode, $\mathrm{GaP}, \mathrm{Ag} / \mathrm{AgCl}$ (sat'd $\mathrm{KCl}$ ) reference electrode, and a Pt mesh counter electrode immersed in $0.1 \mathrm{M} \mathrm{H}_{2} \mathrm{SO}_{4}$ $(\mathrm{pH} 1.1)$. 

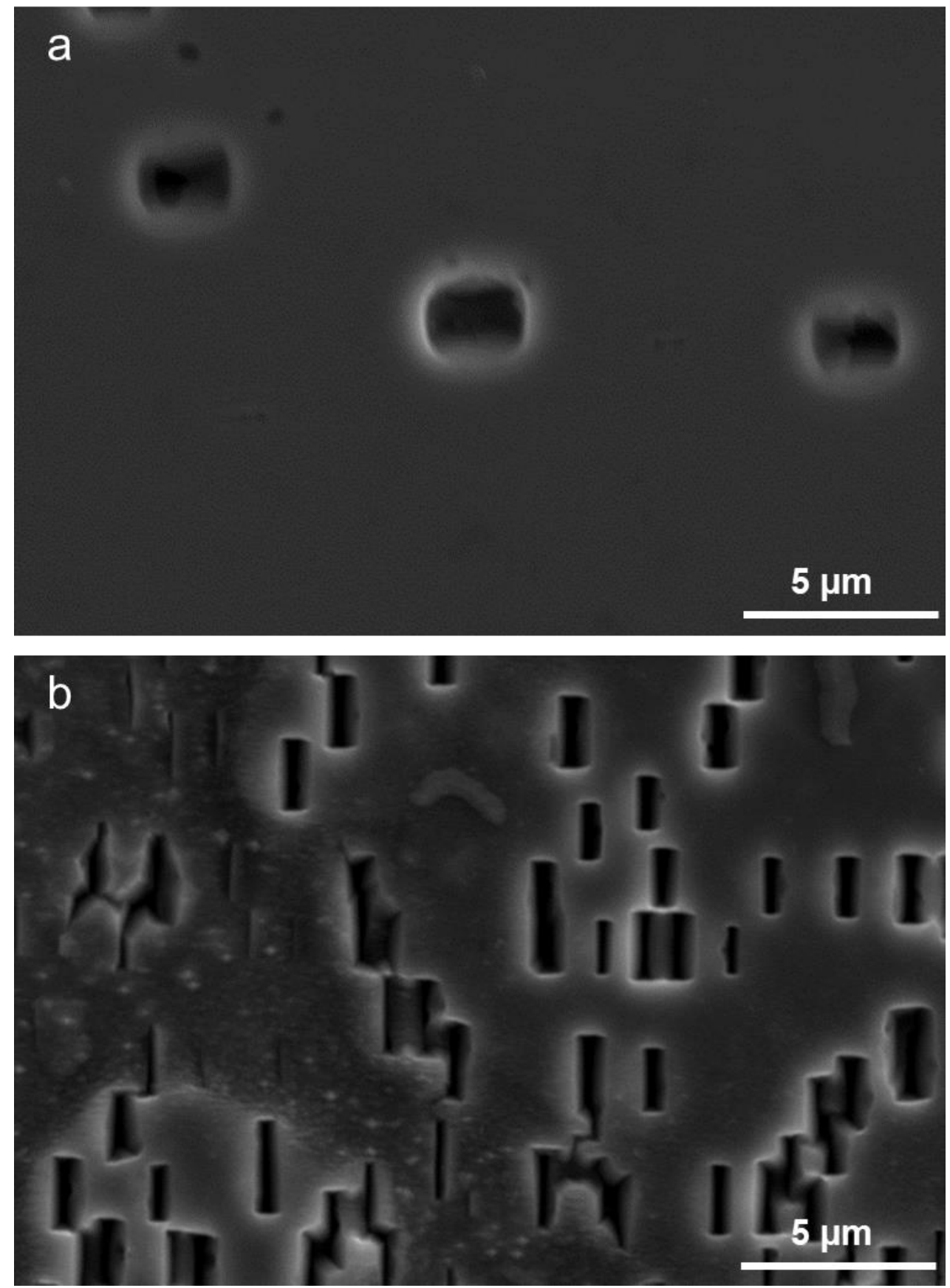

Supplementary Information Figure S12. Magnified SEM images of the surface for a. $\mathrm{Si} / \mathrm{GaP}_{-} \mathrm{TiO}_{2}-\mathrm{MoS}_{2}$ and b. $\mathrm{Si} / \mathrm{GaP}_{-}-\mathrm{TiO}_{2}-\mathrm{Pt}$ after reliability test (> 3h). 
a
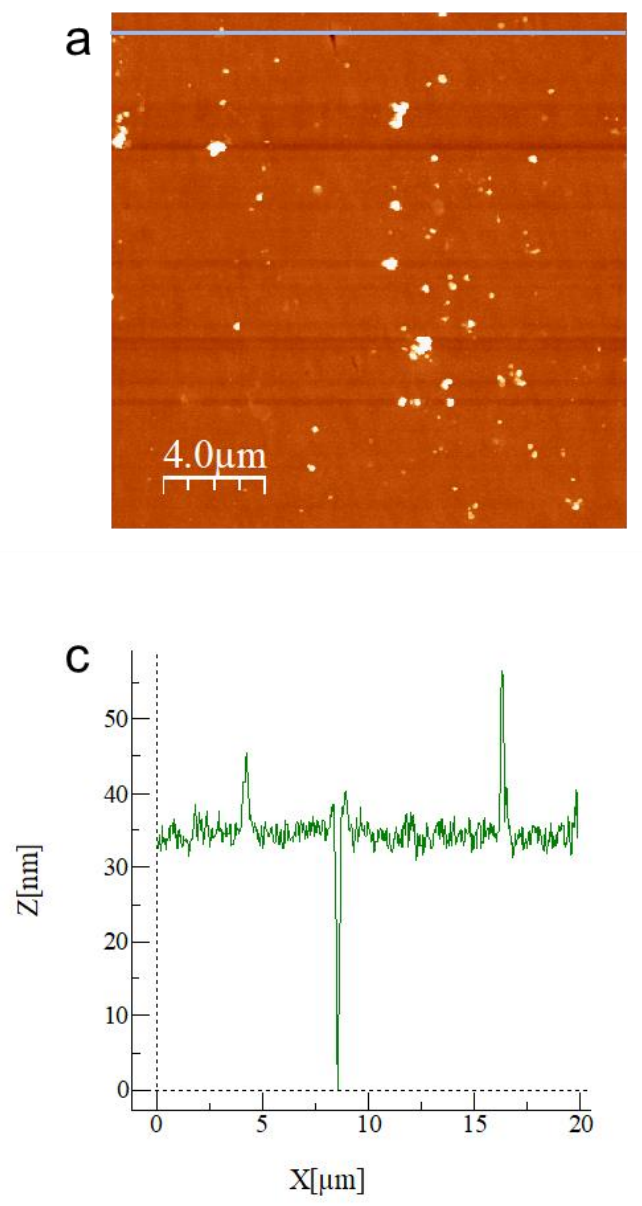

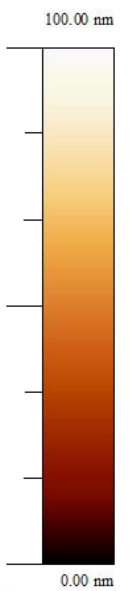

b
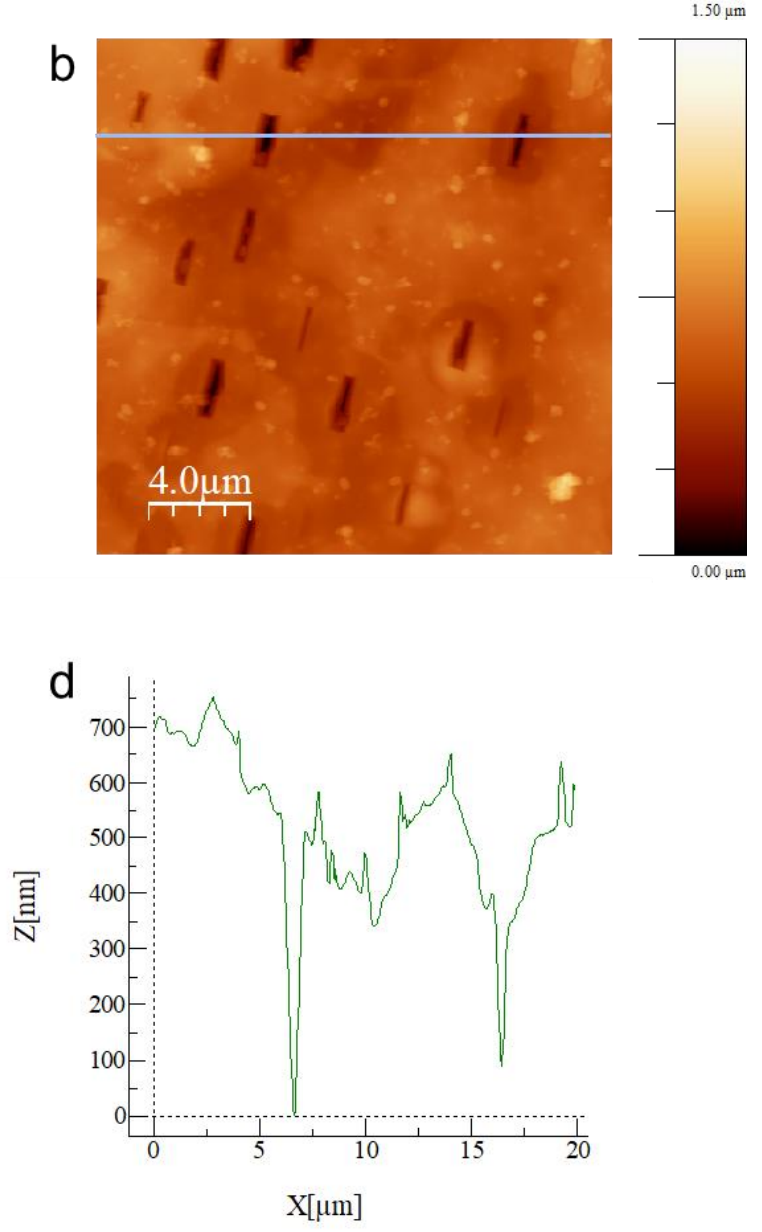

Supplementary Information Figure S13. $20 \mu \mathrm{m} \times 20 \mu \mathrm{m}$ AFM surface morphology the photoelectrodes after reliability test (> 3h): a. $\mathrm{Si} / \mathrm{GaP}-\mathrm{TiO}_{2}-\mathrm{MoS}_{2}$ and b. $\mathrm{Si} / \mathrm{GaP}-\mathrm{TiO}_{2}-\mathrm{Pt}$. AFM line profile of the photoelectrode surfaces after reliability test: c. Si/GaP-TiO $2-\mathrm{MoS}_{2}$

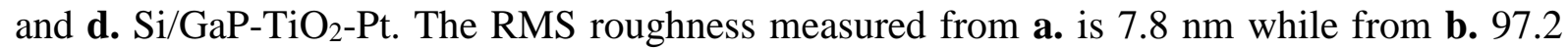
$\mathrm{nm}$. The depth of etching pits on the $\mathrm{Si} / \mathrm{GaP}-\mathrm{TiO}_{2}-\mathrm{MoS}_{2}$ photocathode is about $30 \mathrm{~nm}$. In contrast, the pits are as deep as $500 \mathrm{~nm}$ on the $\mathrm{Si} / \mathrm{GaP}-\mathrm{TiO}_{2}-\mathrm{Pt}$ surface. 